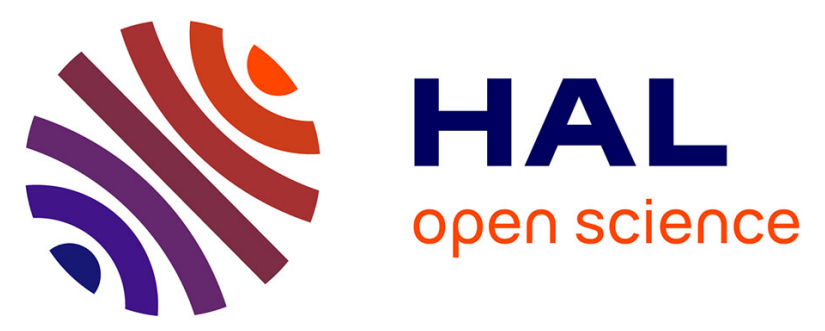

\title{
Polyoxometalate, Cationic Cluster, and $\gamma$-Cyclodextrin: From Primary Interactions to Supramolecular Hybrid Materials
}

Mhamad Aly Moussawi, Nathalie Leclerc-Laronze, Sébastien Floquet, Pavel A. Abramov, Maxim N. Sokolov, Stéphane Cordier, Anne Ponchel, Eric

Monflier, Hervé Bricout, David Landy, et al.

\section{To cite this version:}

Mhamad Aly Moussawi, Nathalie Leclerc-Laronze, Sébastien Floquet, Pavel A. Abramov, Maxim N. Sokolov, et al.. Polyoxometalate, Cationic Cluster, and $\gamma$-Cyclodextrin: From Primary Interactions to Supramolecular Hybrid Materials. Journal of the American Chemical Society, 2017, 139 (36), pp.12793-12803. 10.1021/jacs.7b07317 . hal-01614767

\section{HAL Id: hal-01614767}

\section{https://hal-univ-rennes1.archives-ouvertes.fr/hal-01614767}

Submitted on 5 Dec 2017

HAL is a multi-disciplinary open access archive for the deposit and dissemination of scientific research documents, whether they are published or not. The documents may come from teaching and research institutions in France or abroad, or from public or private research centers.
L'archive ouverte pluridisciplinaire HAL, est destinée au dépôt et à la diffusion de documents scientifiques de niveau recherche, publiés ou non, émanant des établissements d'enseignement et de recherche français ou étrangers, des laboratoires publics ou privés. 


\title{
Polyoxometalate, Cationic Cluster and $\gamma$-Cyclodextrin. From Primary Interactions to Supramolecular Hybrid Materials
}

\author{
Mhamad Aly Moussawi, ${ }^{\dagger}$ Nathalie Leclerc-Laronze,${ }^{\dagger}$ Sébastien Floquet, ${ }^{\dagger}$ Pavel A. Abramov, $,{ }^{f},{ }^{\mathfrak{f}}$ Max- \\ im, N. Sokolov, ${ }^{\ddagger},{ }^{£}$ Stéphane Cordier,§ Anne Ponchel, ${ }^{\ddagger}$ Eric Monflier, ${ }^{\ddagger}$ Hervé Bricout, ${ }^{\ddagger}$ David Landy,${ }^{\jmath}$ \\ Mohamed Haouas, ${ }^{* \dagger}$ Jérôme Marrot, ${ }^{\dagger}$ and Emmanuel Cadot*† \\ †Institut Lavoisier de Versailles UMR 8180, UVSQ, Université Paris-Saclay, 78035 Versailles, France. \\ $\S$ Institut des Sciences Chimiques de Rennes UMR 6226, Université de Rennes 1, 35042 Rennes, France. \\ ‡ Univ. Artois, CNRS, Centrale Lille, ENSCL, Univ. Lille, UMR 8181, Unité de Catalyse et Chimie du Solide, 62300 Lens, France \\ $\int$ Unité de Chimie Environnementale et Interactions sur le Vivant EA 4492, SFR Condorcet FR CNRS 3417, Université du Littoral Côte \\ d'Opale, 59140 Dunkerque, France. \\ f Nikolaiev Institute of Inorganic Chemistry SB RAS, Novosibirsk, 630090, Russia. \\ $£$ Novosibirsk State University, Novosibirsk, 630090, Russia.
}

\section{Supporting Information Placeholder}

ABSTRACT: Herein, we report on a three-component supramolecular hybrid system built from specific recognition processes involving a Dawson type polyoxometalate $\left[\mathrm{P}_{2} \mathrm{~W}_{18} \mathrm{O}_{62}\right]^{6-}$, a cationic electron-rich cluster $\left[\mathrm{Ta}_{6} \mathrm{Br}_{12}\left(\mathrm{H}_{2} \mathrm{O}\right)_{6}\right]^{2+}$ and $\gamma$-cyclodextrin. Investigations of such a class of materials have been conducted using bottom-up approach by studying the specific interactions between $\gamma$-CD and both types of inorganic units. Their ability to interact has been investigated in the solid state by single-crystal X-ray diffraction and in solution using multinuclear NMR methods (including DOSY, EXSY and COSY), ESI-mass and UV-vis spectroscopies, electrochemistry and ITC experiments. Singlecrystal X-Ray diffraction analysis reveals that POM : $\gamma$-CD constitutes a highly versatile system which gives aggregates with the 1:1, 1:2 and 1:3 stoichiometry. Surprisingly, these arrangements exhibit common feature wherein the $\gamma$-CD moiety interact with the Dawson-type polyoxometalates through its primary face. We present also the first structural model involving octahedral-type metallic cluster with $\gamma$-CD. X-ray diffraction study reveals that the cationic $\left[\mathrm{Ta}_{6} \mathrm{Br}_{12}\left(\mathrm{H}_{2} \mathrm{O}\right)_{6}\right]^{2+}$ ion is closely embedded within two $\gamma$ $\mathrm{CD}$ units to give a supramolecular ditopic cation, suitable to be used as linker within extended structure. Solution study demonstrates clearly that pre-associations exist in solution for which binding constants and thermodynamic parameters have been determined, giving preliminary arguments about the chaotropic nature of the inorganic ions. Finally, both building blocks i.e. the ditopic supramolecular cation $\left\{\left[\mathrm{Ta}_{6} \mathrm{Br}_{12}\left(\mathrm{H}_{2} \mathrm{O}\right)_{6}\right] @ 2 \mathrm{CD}\right\}^{2+}$ and the Dawson-type anion react together to give three-component wellordered hybrid material derived either as supramolecular hydrogel or single-crystals. Solid state structure shows an unprecedented helicoidal tubular chain resulting from the periodic alternation of POM and supramolecular cation, featured by short hydrogen bonding contact between electron-poor POM and electron-rich cluster. The 1D tubular ionic polymer observed in the singlecrystals should allow understanding the long-range ordering observed within the hydrogel hybrid material. The supramolecular chemical complementarities between the $\gamma$-CD- based ditopic cation and polyoxometalate open a wide scope for the design of hybrid materials that cumulate synergistic functionalities.

\section{INTRODUCTION}

Motivation to design sophisticated hybrid materials has directed great attention for the development of challenging scientific projects such as those based on mimicking natural processes involved within energy conversion, biomass valorization or pollutants elimination. ${ }^{1}$ Understanding the primary interactions that govern the assembling between molecular components is probably the key for controlling the hierarchical arrangement of complementary active moieties from solution to the functioning material. ${ }^{2}$ In nature, active components are spatially well-ordered to provide the highest efficiency for energy transfer, electrons exchange or catalytic transformation. ${ }^{3}$ For examples, metallic clusters involved in redox bioprocesses such as nitrogen fixation, $\mathrm{CO}_{2}$ reduction or respiration are ubiquitous in biology but generally, they are included within highly evolved biochemical environment to perform electron-transferring functions through complex pathways. ${ }^{4}$ Intense research efforts are deployed in the design of artificial devices integrating active core within simplified biological-like environment. In context, supramolecular chemistry is developing basic concepts and principles that are useful tools to assemble specifically molecular units through weak interactions arising from directed hydrogen bonding, electrostatic or dispersion forces. ${ }^{5}$ In addition to these weak attractive effects, polar solvents such as water contribute substantially to the aggregation processes. Desolvation or solvent reorganization around the guest or within the host can be the most determining contribution in shifting the binding equilibrium. ${ }^{6}$ In many cases, the so-called hydrophobic effect was found to be one of the main driving forces in aqueous medium able to dictate host-guest association, selfassembly processes or ionic recognition. ${ }^{7}$ Polyoxometalates (POMs) are anionic all-inorganic molecular metal oxides with highly diverse structures that reach in size nanoscopic dimensions. 
${ }^{8}$ This class of compounds exhibits a wide structural diversity in relationship with their remarkable chemical and physical properties that make them useful for applications in areas ranging from materials science, and energy conversion to catalysis and medicine. ${ }^{9}$ Therefore, wider exploitation of POM compounds requires the development of robust and efficient synthetic protocols for their integration into hybrid architectures and devices. In context, supramolecular approach has the intrinsic advantage to self-

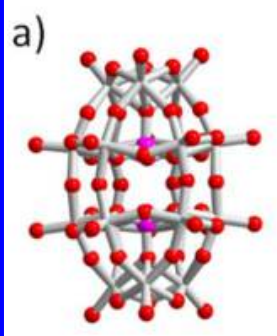

b)

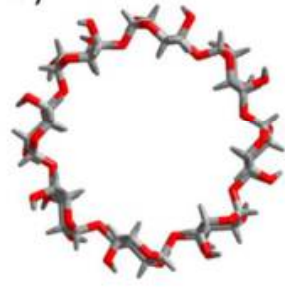

c)

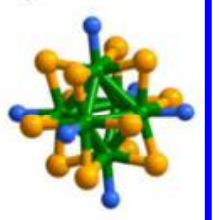

Figure 1. Structural representation of the molecular components used as building blocks : a) Dawson anion $\left[\mathrm{P}_{2} \mathrm{~W}_{18} \mathrm{O}_{62}\right]^{6-}(\mathrm{POM})$ b) $\gamma$ cyclodextrin $\mathrm{C}_{48} \mathrm{H}_{80} \mathrm{O}_{40} \quad(\gamma-\mathrm{CD})$ and c) octahedral cluster $\left[\mathrm{Ta}_{6} \mathrm{Br}_{12}\left(\mathrm{H}_{2} \mathrm{O}\right)_{6}\right]^{2+}\left(\left\{\mathrm{Ta}_{6}\right\}\right)$.

assemble these POM units through weak and specific interactions into well-ordered hierarchical materials. Recently, cyclodextrin has proved to behave as specific glue to assemble POM units to give $1 \mathrm{D}$ nanogrid assembly ${ }^{10}$ or crystalline materials. ${ }^{11}$ Herein, we report on the formation of extended hybrid materials based on the anionic Dawson-type polyoxometalate $\alpha-\left[\mathrm{P}_{2} \mathrm{~W}_{18} \mathrm{O}_{62}\right]^{6-}$ (denoted $\mathrm{POM})$ and the cationic cluster $\left[\mathrm{Ta}_{6} \mathrm{Br}_{12}\left(\mathrm{H}_{2} \mathrm{O}\right)_{6}\right]^{2+}$ (abbreviated $\left.\left\{\mathrm{Ta}_{6}\right\}\right)$ mediated through specific interactions with $\gamma$-cyclodextrin (see Figure 1). The inorganic moieties i.e. POM and octahedral cluster $^{12}$ are two complementary units in term of ionic charge and electronic density. Polyoxotungstates such as the archetypical Dawson anion $\left[\mathrm{P}_{2} \mathrm{~W}_{18} \mathrm{O}_{62}\right]^{6-}$ contain tungsten atoms in their $+\mathrm{VI}$ highest oxidation number and are considered usually as electronpoor polynuclear complexex as exemplified by their ability to undergo multielectron reduction without significant structural changes. On the contrary, the aqua hexatantalum cationic species $\left[\mathrm{Ta}_{6} \mathrm{Br}_{12}\left(\mathrm{H}_{2} \mathrm{O}\right)_{6}\right]^{2+}$ exhibits low oxidation states Ta ${ }^{\mathrm{II}, \mathrm{III}}$ mixed valence centers giving rise to electron-rich metal-metal bonds and related oxidation processes without damaging the cluster structure. In general, octahedral clusters in general represent an important class of compounds in the field of solid state chemistry. ${ }^{13}$ Nevertheless, sophisticated solution chemistry, ranging from coordination chemistry ${ }^{14}$ to supramolecular material ${ }^{15}$ can be also developed from octahedral-type clusters allowing investigating a large panel of applications in photocatalysis, ${ }^{16}$ soft materials, ${ }^{17}$ bio-imaging ${ }^{18}$ or phototherapy. ${ }^{19}$

The $\gamma$-cyclodextrin (noted $\gamma$-CD hereafter) as organic unit is a cyclic oligosaccharide built on eight 1,4-linked D-glucopyranosyl residues which delimit a toroidal hydrophobic cavity. Their remarkable inclusion properties have given rise to wide applications in many fields of science such as nanotechnology, ${ }^{20}$ pharmaceutics $^{21}$ or medicine. ${ }^{22}$ Thus CDs represent an interesting class of building blocks for the construction of hybrid assemblies. ${ }^{23}$ In this report, we show first of all the existence of relevant supramolecular associations between $\gamma$-CD and POM and between $\gamma-\mathrm{CD}$ and $\left\{\mathrm{Ta}_{6}\right\}$ separately in aqueous solutions as well in the solid state. Most importantly, we demonstrate that such interactions could be combined in a rational way to give rise ordered supramolecular hybrid organic-inorganic network based on $\left[\mathrm{P}_{2} \mathrm{~W}_{18} \mathrm{O}_{62}\right]^{6-} /\left\{\mathrm{Ta}_{6}\right\}^{2+}$ $/ \gamma$-CD as primary building units.

\section{RESULTS AND DISCUSSION}

\subsection{Formation of the $\gamma$-CD based adducts}

POM@nCD. Systematic studies have been carried out using different ratios of POM and $\gamma-\mathrm{CD}$ and different alkali salts of the Dawson anion allowing either to tune solubility of the POM $/ \gamma$ $\mathrm{CD}$ aggregates or to improve the quality of the single crystals. This study showed that this chemical system is highly flexible producing crystalline solids which contain aggregates with variable POM : $\gamma$-CD stoichiometries. The syntheses were straightforward and consist of mixing one, two or three equivalents of $\gamma-C D$, respectively dissolved in water or in 0.5 mol. $\mathrm{L}^{-1} \mathrm{NaCl}$ aqueous solution containing one equivalent of Dawson anion $\left[\mathrm{P}_{2} \mathrm{~W}_{18} \mathrm{O}_{62}\right]^{6-}$ at concentration of about $10^{-2} \mathrm{~mol} . \mathrm{L}^{-1}$ as potassium, rubidium or cesium salts. Nature of these alkali cation is expected to tune the solubility of the POM-CD aggregate, thus favoring selective crystallization of the $1: 1,1: 2$ or $1: 3$ assembly. Solutions were allowed to stand at room temperature for crystallization. After several days, single-crystals suitable for XRD, elemental analysis and further characterizations were collected. Further details for the synthetic procedures and routine characterization are given in the Supporting Information (see Supporting Information, §2). Then, the three isolated crystalline phases with the respective composition $\quad \mathrm{KNa}_{5}\left[\mathrm{P}_{2} \mathrm{~W}_{18} \mathrm{O}_{62}\right] \cdot[\gamma-\mathrm{CD}] \cdot 3.5 \mathrm{NaCl} \cdot 23 \mathrm{H}_{2} \mathrm{O}$, $\mathrm{CsNa}_{5}\left[\mathrm{P}_{2} \mathrm{~W}_{18} \mathrm{O}_{62}\right] \cdot[\gamma-\mathrm{CD}]_{2} \cdot 1.2 \mathrm{NaCl} \cdot 23 \mathrm{H}_{2} \mathrm{O}$ and $\mathrm{Rb}_{4} \mathrm{~K}_{1.5} \mathrm{Na}_{0.5}\left[\mathrm{P}_{2} \mathrm{~W}_{18} \mathrm{O}_{62}\right] \cdot[\gamma-\mathrm{CD}]_{3} \cdot 35 \mathrm{H}_{2} \mathrm{O}$ have been abbreviated hereafter POM@CD, POM@2CD and POM@3CD, respectively.

$\left\{\mathrm{Ta}_{6}\right\} @ 2 \mathbf{C D}$. The cationic cluster $\left[\mathrm{Ta}_{6} \mathrm{Br}_{12}\left(\mathrm{H}_{2} \mathrm{O}\right)_{6}\right]^{2+}$ showed high tendency to form a 1:2 inclusion complex with cyclodextrins whatever the used $\left\{\mathrm{Ta}_{6}\right\} / \gamma-\mathrm{CD}$ ratio. The formation of the $1: 2$ adduct is nearly quantitative from aqueous mixtures containing stoichiometric proportion of $\gamma-\mathrm{CD}$ and $\left\{\mathrm{Ta}_{6}\right\}$ cluster. The resulting solutions were able to generate greenish plate crystals corresponding to $\left[\mathrm{Ta}_{6} \mathrm{Br}_{12}\left(\mathrm{H}_{2} \mathrm{O}\right)_{6}\right] \cdot[\gamma-\mathrm{CD}]_{2} \mathrm{Br}_{2} \cdot 14 \mathrm{H}_{2} \mathrm{O}$, namely $\left\{\mathrm{Ta}_{6}\right\} @ 2 \mathrm{CD}$ (see SI $\S 2$ for further details).

\subsection{Single-crystal X-ray analysis}

POM@nCD arrangements with $n=1,2$ or 3 . Remarkably, Xray diffraction analysis of single crystals obtained from POM $/ \gamma$ $\mathrm{CD}$ mixtures revealed three different stoichiometries depending on the used $\mathrm{POM} / \gamma-\mathrm{CD}$ ratio (see Figure 2). Interestingly, structural analyses in the solid state of the $1: 1,1: 2$ and 1:3 arrangements exhibit a striking common mode of interaction in which the two components are held together through close contacts involving the primary face of the $\gamma$-CD and the longitudinal side of the POM. As generally depicted for such a type of arrangements, the two components are held together through a set of weak attractive interactions including electrostatic, ion-dipole and hydrogen bonding (see Figure S3-S5, SI §4). In the structure of the 1:1 complex (see Figure 2a), the Dawson ion appears literally put down on the primary face of the $\gamma-\mathrm{CD}$. Structural analyses revealed only one short ion-dipole contact $\mathrm{W}=\mathrm{O} \cdot \cdots \mathrm{C}-\mathrm{OH}(\mathrm{O} \bullet \mathrm{C}=$ $2.68 \AA$ ), while the remaining similar interactions appear weaker as reflected by $\mathrm{O} \cdots \mathrm{C}$ distances longer than $3.2 \AA$ A Furthermore, four weak hydrogen bonding contacts are observed leading to $\mathrm{O} \cdots \mathrm{O}$ distances in the 3.0-3.3 $\AA$ range. Finally, electrostatic interactions must also be considered since attractive interactions are reinforced 
by $\mathrm{O} \cdots \mathrm{K} \cdots \mathrm{O}$ junctions involving terminal $\mathrm{W}=\mathrm{O}$ groups of the POM unit $(\mathrm{O} \cdots \mathrm{K}$ distances, $\sim 3.0 \AA)$ and by ether or methanolic groups of the glucopyranose moieties belonging to the $\gamma-\mathrm{CD}$. The structure of POM@2CD assembly derives from the former and consists of one Dawson unit $\left[\mathrm{P}_{2} \mathrm{~W}_{18} \mathrm{O}_{62}\right]^{6-}$ sandwiched by two $\gamma$ $\mathrm{CD}$ disnosed on the two onnosite lonoitudinal faces of the POM at

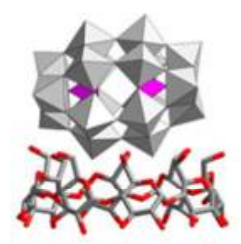

a)
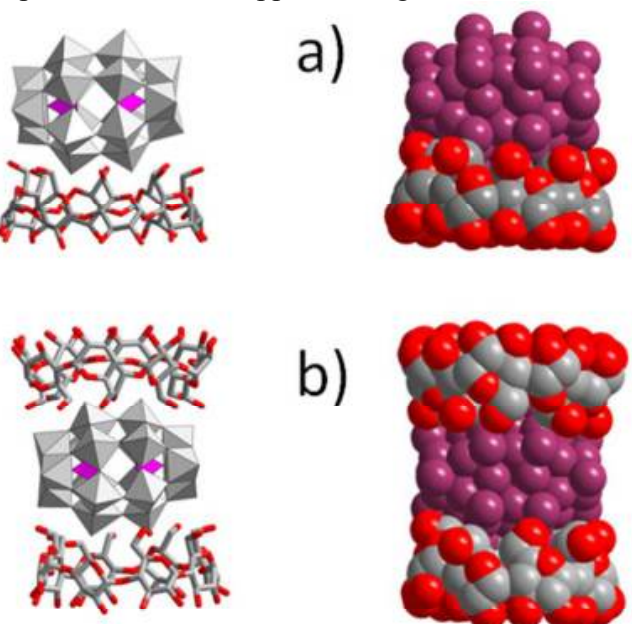

b)
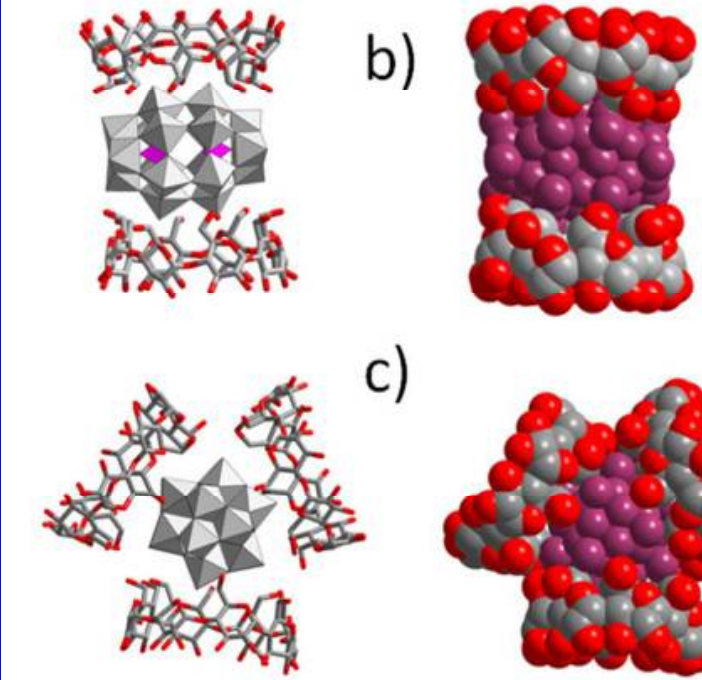

c)

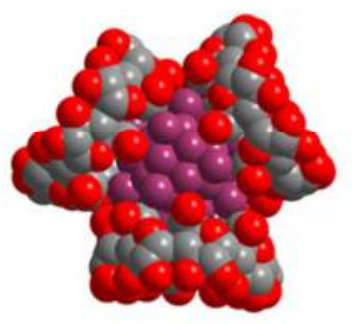

Figure 2. Structural representation of the supramolecular POM@nCD along their X-ray diffraction analysis showing a) the 1:1, b) 1:2 and c) 1:3 arrangements.

$180^{\circ}$ from each other (see Figure $2 \mathrm{~b}$ ). The cohesion forces of the supramolecular 1:2 arrangement are ensured by three hydrogen bonding contact with $\mathrm{O} \cdots \mathrm{O}$ distances of about $3.0 \AA$, supported by electrostatic interactions involving bridging $\mathrm{Na}^{+}$and $\mathrm{Cs}^{+}$cation (see Figure S4, SI §4). A third POM: $\gamma$-CD stoichiometry has been obtained giving an assembly where the $\left[\mathrm{P}_{2} \mathrm{~W}_{18} \mathrm{O}_{62}\right]^{6-}$ ion is closely embedded by three $\gamma-\mathrm{CD}$ as a paddle wheel arrangement (see Figure 2c). As already observed for the 1:1 and 1:2 stoichiometries, the primary faces of the three $\gamma$-CD units are directed toward the central POM moiety. Interestingly, the three $\gamma-\mathrm{CD}$ are related through a $\mathrm{C}_{3}$ axis and held together through three short hydrogen bonding contacts $(\mathrm{O} \cdots \mathrm{O}=2.69 \AA)$. Furthermore, three equivalent rubidium cations are also involved within the POM@3-CD arrangement, as nodes that associate the POM with two $\gamma$-CD through seven $\mathrm{Rb}-\mathrm{O}$ contacts $(\mathrm{Rb}-\mathrm{O}=2.83-3.22 \AA)$ (see Figure S5, SI §4). At last, three additional hydrogen-bonds $(\mathrm{O} \cdots \mathrm{O}=2.93 \AA)$ ensure direct interactions between POM and $\gamma-$ $\mathrm{CD}$. These results have to be correlated with those previously reported by Stoddart et al. on superstructures involving cyclodextrins and the Keggin-type $\left[\mathrm{PMo}_{12} \mathrm{O}_{40}\right]^{3-}$ anion. ${ }^{11}$ In all cases, the three structures exhibit similar types of molecular recognition wherein POM unit is facing $\gamma$-CD through its primary face as two complementary moieties usually described as hydrogen bond acceptor and donor, respectively. In these structural examples, the Keggin or Dawson ions do not penetrate deeply into the cavity of the macrocyclic host but rather interact through multiple weakly bonding interactions array with the hydrophilic $\mathrm{OH}$ groups lining the primary faces of the CDs. Actually, such a situation is significantly pronounced with the Dawson anion, a species larger than the $\left[\mathrm{PMo}_{12} \mathrm{O}_{40}\right]^{3-}$ Keggin-type anion. ${ }^{11}$ Besides, it should be also worth noting the role of the alkali ions $\left(\mathrm{Na}^{+}, \mathrm{K}^{+}, \mathrm{Rb}^{+}\right.$or $\left.\mathrm{Cs}^{+}\right)$, which participate also in the reinforcement of the supramolecular POM $\cdots \mathrm{CD}$ associations in the solid state packing. Nevertheless, Stoddart et al. mentioned that the $\mathrm{La}^{3+}$ counter cation presents as fully hydrated aqua ion $\left[\mathrm{La}\left(\mathrm{H}_{2} \mathrm{O}\right)_{9}\right]^{3+}$ displays only very weak ionic interactions with the $\left[\mathrm{PMo}_{12} \mathrm{O}_{40}\right] @ 2 \mathrm{CD}$ supramolecular complexes. In our case, probably due to their low enthalpy hydration, ${ }^{24}$ alkali ions are then able to interact directly with the $\mathrm{OH}$ groups of the rims (see Figure S3-S5, SI §4). In this case, such a situation precludes the usual face-to-face organization observed within the $\left[\mathrm{PMo}_{12} \mathrm{O}_{40}\right] @ 2 \mathrm{CD}$ arrangement. ${ }^{11}$ At last, it should be mentioned that in the 3D packing of the POM@2-CD and POM@3-CD, some close contacts and partial inclusions between $\gamma$-CDs can be depicted in addition to the POM $\cdots \cdot \mathrm{CD}$ interactions.

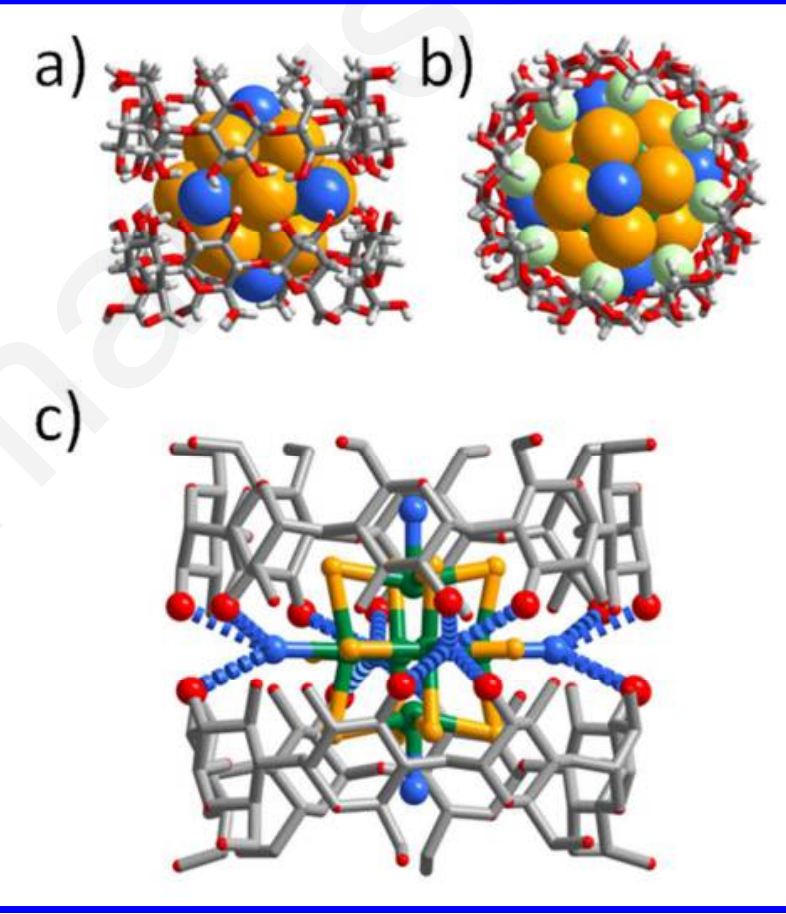

Figure 3. Mixed representations of the solid state structure of the supramolecular host-guest $\left\{\left[\mathrm{Ta}_{6} \mathrm{Br}_{12}\left(\mathrm{H}_{2} \mathrm{O}\right)_{6}\right] @ 2 \gamma-\mathrm{CD}\right\}^{2+}$ complex : a) side view and $b$ ) top view highlighting close interactions between inner H-3 hydrogen (white sphere) and four bromide ligands (yellow sphere) with $\mathrm{H} \cdots \mathrm{Br}=2.83 \AA$; c) focus on the intermolecular hydrogen bonding network involving the four in plane aquo ligands of the cluster and the hydroxo groups of $\gamma-\mathrm{CD}$ secondary faces $(\mathrm{O} \bullet \bullet \mathrm{O}=3.0$ $-3.1 \AA)$.

$\left\{\mathbf{T a}_{6}\right\} @ \cdot 2 \mathrm{CD}$ arrangement. The supramolecular host-guest arrangement within $\left[\mathrm{Ta}_{6} \mathrm{Br}_{12}\left(\mathrm{H}_{2} \mathrm{O}\right)_{6}\right] \cdot[\gamma-\mathrm{CD}]_{2} \mathrm{Br}_{2} \bullet 14 \mathrm{H}_{2} \mathrm{O}$ crystal is depicted in Figure 3 . The structural analysis reveals a $\left[\mathrm{Ta}_{6} \mathrm{Br}_{12}\left(\mathrm{H}_{2} \mathrm{O}\right)_{6}\right]^{2+}$ cluster closely embedded into two $\gamma$-CDs interacting mutually through multiple hydrogen-bonds $(\mathrm{O} \bullet \bullet \mathrm{O}=2.9$ $3.0 \AA$ ) involving their wider rim (secondary face). Structural 
parameters of the encapsulated $\left\{\mathrm{Ta}_{6}\right\}$ cluster remain in the usual range of that generally observed $(\mathrm{Ta}-\mathrm{Ta}=2.88-2.93 \AA$; Ta $\mathrm{Br}=2.60-2.61 \AA ; \mathrm{Ta}-\mathrm{O}=2.15-2.39 \AA) .{ }^{25 a-c}$ However, the cohesion of the supramolecular assembly arises from four short $\mathrm{C}-\mathrm{H} \cdots$ Br contacts $(\mathrm{H} \cdots \mathrm{Br}=2.83 \AA)$ involving the inner $\mathrm{H}-3$ hydrogen atoms of each $\gamma-\mathrm{CD}$ and the $\mathrm{Br}$ atoms of the cluster (see Figure $3 b$ ). In addition, the host-guest stability is supported by a framework of 16 hydrogen bonds connecting the four in-plane aquo ligands of the $\left\{\mathrm{Ta}_{6}\right\}$ cluster with the four closest $\mathrm{OH}$ groups $(\mathrm{O} \cdots \mathrm{O}=3.0-3.1 \AA)$ that line the secondary face of the two $\gamma-\mathrm{CD}$ (see Figure $3 \mathrm{c}$ ). As resulting from the multiple intermolecular weak interactions and host-guest disposition, the two stacked $\gamma$ CDs appear slightly staggered of about $21^{\circ}$ leading to an overall $\mathrm{D}_{4}$ idealized symmetry. Besides, the tetragonal unit cell displays the common tubular arrangement formed by supramolecular building blocks $\left\{\mathrm{Ta}_{6} @ 2 \mathrm{CD}\right\}$ running along the $c$ axis through short $(\mathrm{O} \cdots \mathrm{O}=2.83 \AA)$ and long $(\mathrm{O} \cdots \mathrm{O}=6.78 \AA)$ inter-blocks distances (see Figure S6, SI §4). ${ }^{11,26}$ At least, it should be mentioned that the electric balance is ensured by two bromide ions per $\left[\mathrm{Ta}_{6} \mathrm{Br}_{12}\left(\mathrm{H}_{2} \mathrm{O}\right)_{6}\right]^{2+}$ cluster. One half is located on eight equivalent disordered positions and closely intercalated within the $\left\{\mathrm{Ta}_{6} @ 2 \gamma\right.$ CD tubes (see Figure S6, SI, §4) while the other half of the $\mathrm{Br}^{-}$ ions is distributed between the tubular assembly. Among the abundant literature on the cyclodextrin-based host-guest arrangements, it should be mentioned the report of Nau et al. about the inclusion complexes of the $\left[\mathrm{B}_{12} \mathrm{X}_{12}\right]^{2-}$ series (with $\mathrm{X}=\mathrm{H}, \mathrm{Cl}, \mathrm{Br}$ or I) who described the crystallographic structure of the $\left[\mathrm{B}_{12} \mathrm{Br}_{12}\right]^{2-}$ dodecaborates included within two $\gamma$-CDs. ${ }^{27}$ Strikingly, both ionic species, i.e. cationic with $\left[\mathrm{Ta}_{6} \mathrm{Br}_{12}\left(\mathrm{H}_{2} \mathrm{O}\right)_{6}\right]^{2+}$ or anionic with $\left[\mathrm{B}_{12} \mathrm{Br}_{12}\right]^{2-}$ appear deeply immersed within two facing $\gamma$-CDs to give similar host-guest arrangements. Furthermore, structural analogies can be also prolonged to the crystal lattices which display the formal tubular network, both consistent with a tetragonal cell in the $I_{422}$ space group. Such an analogy tends to demonstrate

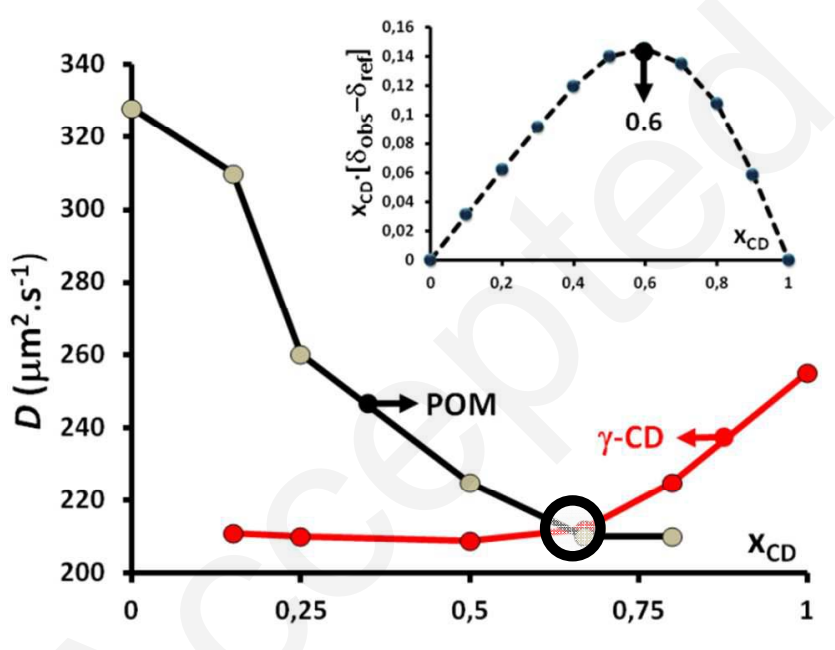

Figure 4. Variation of the self-diffusion coefficient of POM (black curve) and $\gamma$-CD (red curve) measured by ${ }^{31} \mathrm{P}$ and ${ }^{1} \mathrm{H}$ DOSY NMR spectroscopy, respectively. The significant variation of the $D$ values reveals that both $\gamma-\mathrm{CD}$ and POM move together for compositions close the 1:2 ratio $\left(\mathrm{x}_{\mathrm{CD}}=0.66\right)$. Insert : Job's plot for $\gamma-\mathrm{CD}$ and POM obtained by plotting the chemical shift changes $\mathrm{H}-6 / 6$ ' protons of the $\gamma$-CD. that the lattice is mainly imposed by the tubular packing of the large supramolecular ionic units able to accommodate different types of counter-ions in the large resulting voids, such as $\mathrm{Na}^{+}$with $\left[\mathrm{B}_{12} \mathrm{Br}_{12}\right]^{2-}$ or $\mathrm{Br}^{-}$with $\left[\mathrm{Ta}_{6} \mathrm{Br}_{12}\left(\mathrm{H}_{2} \mathrm{O}\right)_{6}\right]^{2+}$. At least, these striking structural similarities are also supported by close solution behavior revealed by NMR, ITC and electrochemical studies (see following sections).

\subsection{Solution studies}

Interactions of $\gamma-\mathrm{CD}$ with POM or $\left[\mathrm{Ta}_{6} \mathrm{Br}_{12}\left(\mathrm{H}_{2} \mathrm{O}\right)_{6}\right]^{2+}$ cluster in aqueous solutions have been confirmed and studied in details by NMR, ESI-MS, ITC measurements, electrochemistry and UV-vis. These studies and related analyses were able to give clear insights about supramolecular pre-organization processes that occur in solution and to draw a comprehensive description of the interplay of the solvation shell within the recognition processes.

NMR studies. Aqueous solutions of $\mathrm{K}_{6}\left[\mathrm{P}_{2} \mathrm{~W}_{18} \mathrm{O}_{62}\right] \cdot 19 \mathrm{H}_{2} \mathrm{O}$ or $\left[\mathrm{Ta}_{6} \mathrm{Br}_{12}\left(\mathrm{H}_{2} \mathrm{O}\right)_{6}\right] \mathrm{Br}_{2}$ mixed with various amounts of $\gamma-\mathrm{CD}$ have been studied by multinuclear NMR (1D, EXSY or DOSY). NMR results showed contrasted behaviors related to the different shape, size and electronic charge density of the inorganic guest species. The ${ }^{1} \mathrm{H}$ NMR spectra of $\gamma-\mathrm{CD}$ upon increasing concentration of the $\left[\mathrm{P}_{2} \mathrm{~W}_{18} \mathrm{O}_{62}\right]^{6-}$ species revealed tiny but significant chemical shift changes which involve mainly the primary face protons $\mathrm{H}$ $6 / 6^{\prime}(\Delta \delta \sim 0.3 \mathrm{ppm}$ ) (see Figure S9, SI $\S 5){ }^{28}$ This observation suggests that the Dawson units interact weakly with the primary face of the $\gamma$-CD to give labile associations in fast chemical exchange regime with respect to the NMR time scale. Furthermore, Job's plot analysis (see insert in Figure 4) allowed concluding that $\gamma-\mathrm{CD} / \mathrm{POM}$ aggregates form in solution with an average stoichiometry close to $1: 2$. In fact, such aggregates formation has been nicely evidenced concomitantly by ${ }^{1} \mathrm{H}$ and ${ }^{31} \mathrm{P}$ DOSY NMR allowing access to the self-diffusion coefficient of the $\gamma$-CD and that of the POM species, respectively. The DOSY investigation, graphically shown in Figure 4 reveals that the self-diffusion coefficients of the interacting substrates decrease significantly in the $\mathrm{POM} / \gamma-\mathrm{CD}$ mixture that underline the formation of stable aggregates in solution. Interestingly, the $D$ value of both interacting components reach together the same minimum value at $D=210$ $\mu \mathrm{m}^{2} . \mathrm{s}^{-1}$ observed for the composition range close to the $1: 2$ ratio $\left(x_{\mathrm{CD}}=0.66\right)$. While the chemical shift changes of the $\gamma-\mathrm{CD}$ are small and those of the ${ }^{31} \mathrm{P}$ or ${ }^{183} \mathrm{~W}$ resonances nearly undetectable (see Figure S7-S8, SI §5), they feature tiny conformational or electronic changes induced through aggregates formation. On the contrary, the DOSY analysis of the POM / $\gamma$-CD mixture revealed clearly that stable aggregates are formed provoking large changes of self-diffusion coefficients (see Figure 4). These DOSY NMR data corroborate nicely the analysis given by Stoddart et al. from SAXS/WAXS measurements carried out on aqueous solution containing the Keggin-type anion and $\gamma$-CD. ${ }^{11}$ Noticeably, apparent contradictions arise from these finding because structural analysis reveals that POMs and CDs assemble together through weak interactions evidenced by only tiny variations of NMR chemical shifts $\left({ }^{1} \mathrm{H},{ }^{183} \mathrm{~W}\right.$ and $\left.{ }^{31} \mathrm{P}\right)$, while DOSY or SAXS/WAXS investigations demonstrate that these hydrophilic species form stable aggregates in aqueous solution. Such an apparent discrepancy shed light on the prominent role of the water molecules as solvent when interacting species like POMs and $\gamma-\mathrm{CD}$ exhibit significant solvent-accessible surface. ${ }^{29}$

In the presence of the octahedral $\left[\mathrm{Ta}_{6} \mathrm{Br}_{12}\left(\mathrm{H}_{2} \mathrm{O}\right)_{6}\right]^{2+}$ cationic cluster, the ${ }^{1} \mathrm{H}$ NMR spectra of the $\gamma$-CD undergoes strong changes characterized mainly by the disappearance of the $\mathrm{H}-1$ and $\mathrm{H}-3$ 
initial resonances of the $\gamma$-CD for the benefit of new signals, (see Figure 5). ${ }^{1} \mathrm{H}$ NMR titration showed that such changes are nearly completed for the 1:2 ratio that is fully consistent with the X-ray diffraction analysis and ITC analysis (see below). The species distribution calculated using the binding constants of ITC measurements in experimental conditions of NMR measurements supports that the prominent species above cluster/CD ratio 0.25 is the $1: 2$ complex and the $1: 1$ species remains negligible in the cluster/CD ratio range studied (see Figure S11 SL S5)

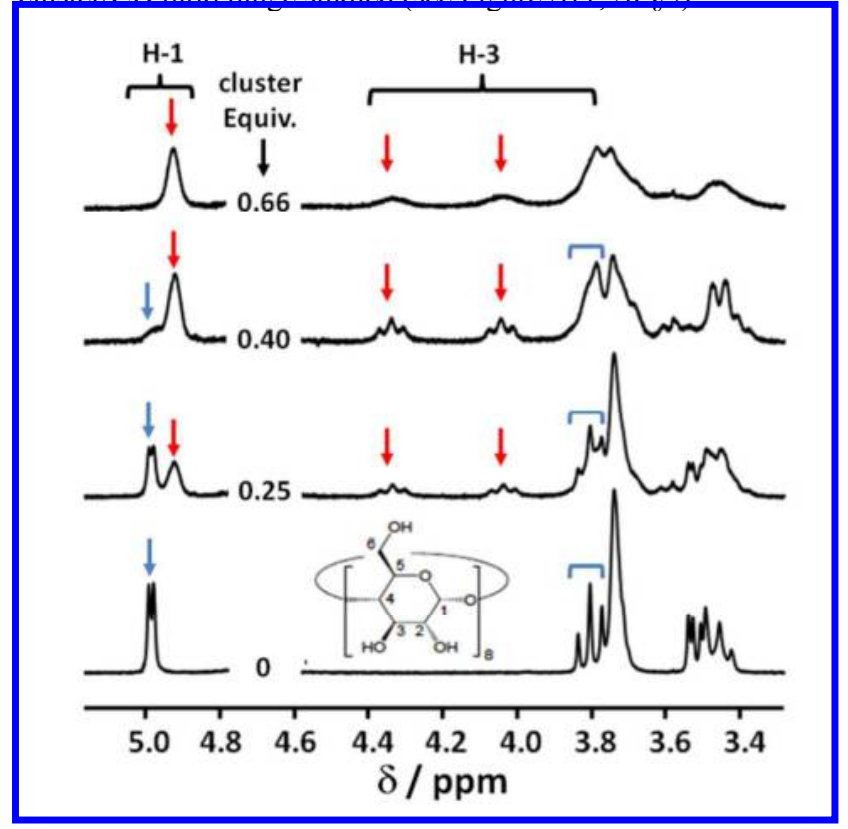

Figure 5. Selected ${ }^{1} \mathrm{H}$ NMR spectra $\left(300 \mathrm{MHz}, 298 \mathrm{~K}, \mathrm{D}_{2} \mathrm{O}, 1 \mathrm{mM}\right)$ of $\gamma-\mathrm{CD}$ in the presence of the different equivalent of $\left\{\left[\mathrm{Ta}_{6} \mathrm{Br}_{12}\left(\mathrm{H}_{2} \mathrm{O}\right)_{6}\right]^{2+}\right.$ dication. Arising of new resonances, clearly observed for the H-1 and H-3 protons suggests that the cluster is deeply inserted into the cavity of the $\gamma-\mathrm{CD}$ at their secondary faces, giving a non-labile 1:2 host-guest arrangement.

Actually, the presence of additional ${ }^{1} \mathrm{H}$ NMR resonances is characteristic of dynamically slow equilibrium process (on the NMR time scale) in $\mathrm{D}_{2} \mathrm{O}$ solution involving deeply embedded tantalum cluster through the two secondary face of

$\gamma$-CD tori. EXSY ${ }^{1} \mathrm{H}$ NMR spectrum (see Figure S12, SI §5), recorded for a 1:1 ratio revealed correlations between resonances of the free and complexed $\gamma-\mathrm{CD}$, both involved in slow exchange processes. Thus, under complexation process, $\mathrm{H}-1$ undergoes a significant low frequency shift giving broader new signal at 4.93 $\mathrm{ppm}$. At the same time, $\mathrm{H}-3$ resonance splits into two signals at 4.34 and $4.05 \mathrm{ppm}$ that reflect the symmetry lowering of the macrocycles in the host-guest arrangement from $\mathrm{C}_{8}$ to $\mathrm{C}_{4}$. Variable temperature ${ }^{1} \mathrm{H}$ NMR experiments carried out at a ratio $\left\{\mathrm{Ta}_{6}\right\} / \gamma-\mathrm{CD}=1: 4$ ratio confirm plentifully such a dynamic behaviors showing illustrative coalescence phenomena from about $50-60{ }^{\circ} \mathrm{C}$ for the most affected $\mathrm{H}-1$ and $\mathrm{H}-3$ signals (see Figure S13, SI §5). Furthermore, analysis of the COSY ${ }^{1} \mathrm{H}$ NMR spectrum of the 1:2 association allowed confirmation of these ${ }^{1} \mathrm{H}$ NMR assignments of the $\gamma$-CD as host (see Figure S14, SI §5). Actually, the significant downfield shifts concomitant to the splitting of the inner H-3 protons appear in fair concordance with that observed by $\mathrm{X}$-ray diffraction analysis. In the solid state structure, four $\mathrm{H}-3$ protons of each $\gamma-\mathrm{CD}$ exhibit very close contacts with four $\mathrm{Br}$ atoms of the tantalum cluster $(\mathrm{Br} \cdot \bullet \cdot \mathrm{H}=2.83 \AA)$, while the four remaining H-3 are engaged within significantly longer interactions $(\mathrm{Br} \bullet \cdot \mathrm{H}=3.19 \AA$ ) (see Figure $3 \mathrm{~b})$. Then, the decrease of the local symmetry of the $\gamma$-CD from $C_{8}$ to $C_{4}$ generates two groups of four equivalent glucopyranosyl units that should provoke the splitting of all the ${ }^{1} \mathrm{H}$ resonances. This is clearly observed for the most affected H-3 protons while line broadening and probably accidental degeneracy prevent any clear resolutions of signals arising from the two sets of nonequivalent glucopyranosyl units. In conclusion, NMR results reveal a frozen complex that should feature a high host-guest affinity. Such a situation is fully consistent with the X-ray structural analysis which reveals a deeply embedded tantalum cluster within the $\gamma$ CDs pocket. These observations have been further supported by ITC analysis (see helow)

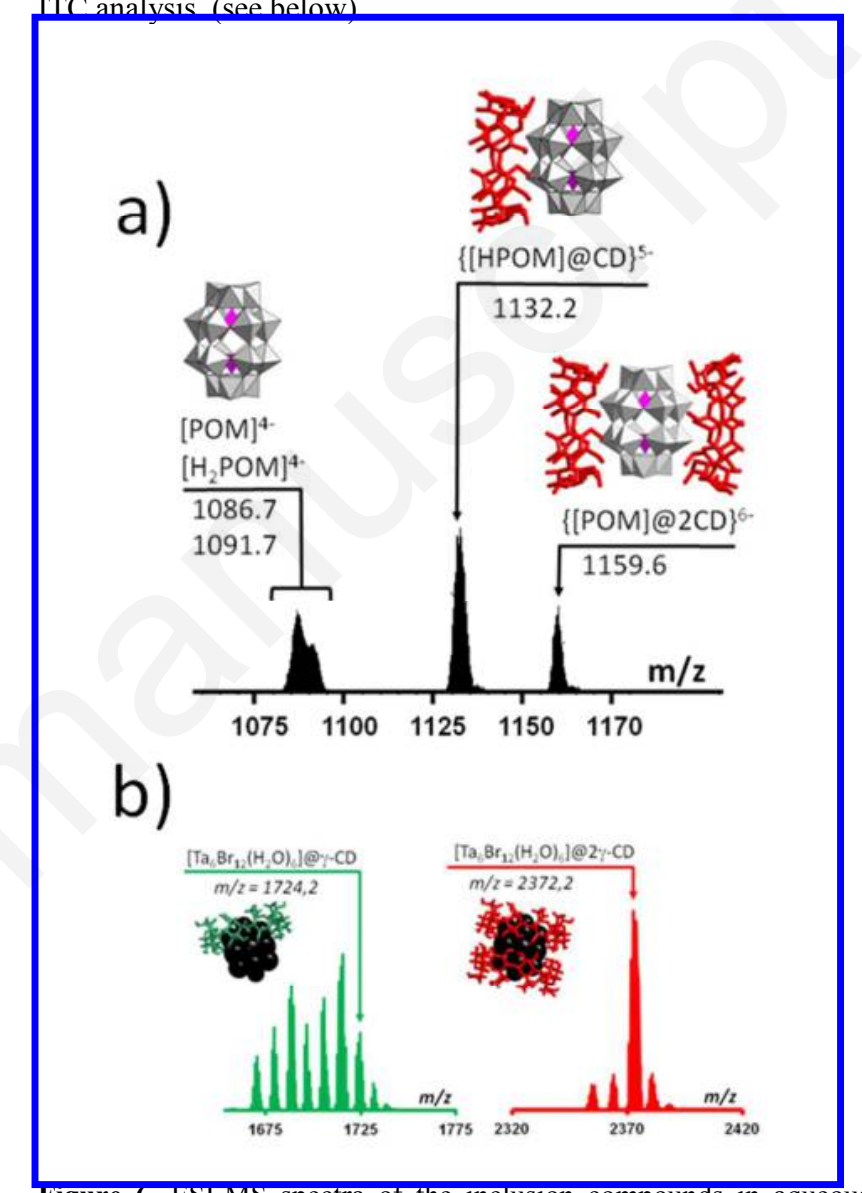

Figure 6. ESI-MS spectra of the inclusion compounds in aqueous solution. (a) POM@3CD showing the 1:1 and the 1:2 adducts while the 1:3 complex is not observed. (b) $\left\{\mathrm{Ta}_{6}\right\} @ 2 \mathrm{CD}$ containing the $\mathrm{m} / \mathrm{z}$ peak related to the 1:2 (red trace) and 1:1 (green trace) adducts. The side peaks separated from each other by $\mathrm{m} / \mathrm{z}=9$ are unambiguously attributed to either hydrated or dehydrated complexes.

ESI-MS studies. The $\gamma$-CD based systems containing either the Dawson anion or the $\left\{\mathrm{Ta}_{6}\right\}$ octahedral dicationic cluster give explicit ESI-MS spectra in fair accordance with our previous results. As shown in Figure 6a, ESI-MS spectrum of $1.10^{-4}$ mol. $L^{-1}$ aqueous solution in POM@3CD assembly, carried out in the negative mode contains three well-defined massifs which have been attributed unambiguously to [POM@2CD] ${ }^{6-}$ at $m / z=1159.6$, [HPOM@CD] ${ }^{5-}$ at $m / z=1132.2$ and CD-free POM identified as $\left[\mathrm{H}_{2} \mathrm{P}_{2} \mathrm{~W}_{18} \mathrm{O}_{62}\right]^{4-}$ at $m / z=1091.4$ and $\left[\mathrm{P}_{2} \mathrm{~W}_{18} \mathrm{O}_{61}\right]^{4-}$ at $m / z=1086.7$. It is quite surprising that such aggregates which have been characterized as labile adduct by ${ }^{1} \mathrm{H}$ NMR can even be observed in the conditions required for ESI-MS experiments. Nevertheless, initial complex POM@3CD was not observed in the ESI-MS spectrum, 
probably due to a weaker stability than that of the smaller aggregates POM@2CD and POM@CD. This is consistent with ITC measurements which indicate also that higher aggregates such as POM@3CD do not contribute significantly within the thermodynamic of the overall host-guest process.

Conversely, the $\left\{\mathrm{Ta}_{6} \mathrm{Br}_{12}\left(\mathrm{H}_{2} \mathrm{O}\right)_{6} @ 2 \mathrm{CD}\right\}^{2+}$ host-guest arrangement in aqueous solution gives a ESI-MS spectrum in the positive mode that contains two main massifs, each characteristic of the $1: 2$ and 1:1 assembly, respectively (see Figure $6 \mathrm{~b}$ and Figure S15, $\S 6)$. The highest $\mathrm{m} / \mathrm{z}$ massif contains peak at 2372.2 corresponding to the expected dicationic $1: 2$ species $\left\{\mathrm{Ta}_{6} \mathrm{Br}_{12}\left(\mathrm{H}_{2} \mathrm{O}\right)_{6} @ 2 \mathrm{CD}\right\}^{2+}$. Furthermore, this peak is flanked on each side by two additional signals giving an overall set of five peaks all separated exactly by $\mathrm{m} / \mathrm{z}=9$ that is consistent with gain or loss of one or two water molecules. Therefore, the two right side-peaks located at $\mathrm{m} / \mathrm{z}=2380$ and 2389 are attributed to monoand dihydrated dicationic derivatives, while the two other peaks located on the left side result from the loss of one or two water molecules. Aqua ligands attached to the octahedral tantalum cluster could be involved and especially the two axial coordination water molecules. These water molecules are directed along the $\gamma$-CD axis and probably more exposed than the four remaining equatorial aqua ligands, intimately encaged within the two $\gamma$-CD tori (see Figure 3). The other massif is constituted of nine peaks corresponding to different hydration state of the 1:1 dication hostguest arrangement. The expected species $\left\{\mathrm{Ta}_{6} \mathrm{Br}_{12}\left(\mathrm{H}_{2} \mathrm{O}\right)_{6} @ \mathrm{CD}\right\}^{2+}$ and related mono- and di-hydrated derivatives are observed at $\mathrm{m} / \mathrm{z}$ $=1724,1733$ and 1742, respectively. On the left side, the presence of six peaks at lower $\mathrm{m} / \mathrm{z}$ value is rather consistent with the sequential dehydration of the octahedral cluster until the loss of the six coordination aqua ligands to give the anhydrous species $\left\{\mathrm{Ta}_{6} \mathrm{Br}_{12} @ \mathrm{CD}\right\}^{2+}$. These ESI-MS results seem to indicate that a supramolecular control of the desolvation process of the $\left[\mathrm{Ta}_{6} \mathrm{Br}_{12}\left(\mathrm{H}_{2} \mathrm{O}\right)_{6}\right]^{2+}$ cluster is allowed, selectively restricted to the two axial aquo ligands within the closed 1:2 arrangement and extended to the six aquo ligands within the opened 1:1 shell. Such ESI-MS observations tend to demonstrate that supramolecular coordination chemistry based on selective ligand exchange process should be achievable from aqua octahedral clusters, using their remarkable host-guest complementarity with $\gamma$-CD.

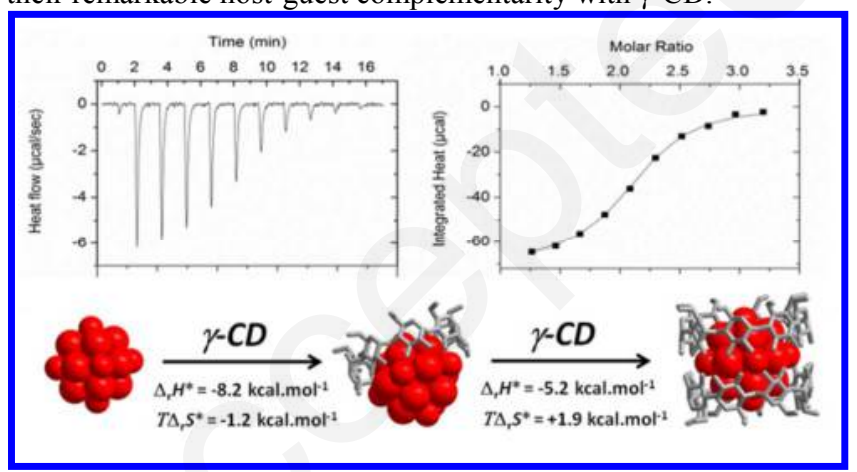

Figure 7. Microcalorimetric titration data obtained at $298 \mathrm{~K}$ from sequential injections of $3.33 \mathrm{mM} \gamma-\mathrm{CD}$ solution into a $0.33 \mathrm{mM}$ $\left[\mathrm{Ta}_{6} \mathrm{Br}_{12}\left(\mathrm{H}_{2} \mathrm{O}\right)_{6}\right] \mathrm{Br}_{2}$ solution showing ITC thermogram (left) and isotherm (right). Dots and full lines correspond to experimental and calculated heats obtained from thermodynamic parameters describing a two-step sequential binding process (bottom).

ITC measurements. ITC was used to analyze from a thermodynamic point of view the interactions of the $\gamma$-CD with POM or $\left[\mathrm{Ta}_{6} \mathrm{Br}_{12}\left(\mathrm{H}_{2} \mathrm{O}\right)_{6}\right]^{2+}$ cluster, respectively. ${ }^{30,26 \mathrm{a}}$ ITC results including binding constants, enthalpy $\Delta_{\mathrm{r}} H^{*}$ and entropy $\Delta_{\mathrm{r}} S^{*}$ are given at $298 \mathrm{~K}$ in Table 1 while further details about ITC experiments are supplied in SI §7. The ITC data obtained from POM $/ \gamma-C D$ system were analyzed using a two-site binding model involved within a sequential process. As X-Ray diffraction data revealed that a 1:3 aggregate POM@3CD can be isolated in the solid state, introducing a third sequence within the binding model does not improve fits significantly between experimental and calculated data. This means that recognition process is mainly dominated by the formation of the 1:1 and 1:2 aggregates and that presence of higher order aggregates remains negligible in solution. Actually, the ITC results confirm nicely the above results showing a quite significant affinity between POM and $\gamma-\mathrm{CD}$ with $K_{11}=3.210^{3} \mathrm{M}^{-1}$ and $\mathrm{K}_{12}=3.710^{2} \mathrm{M}^{-1}$, associated with enthalpy driven processes, each compensated by entropy penalty. It is worth mentioning that these binding constants are of about one order of magnitude lower than those reported by Stoddart et al. for both 1:1 and 1:2 complexes between the $\gamma-\mathrm{CD}$ and the Keggin POM $\left[\mathrm{PMo}_{12} \mathrm{O}_{40}\right]^{3-11}$ This lower affinity with the Dawson-type structure is consistent with the elongated Dawson structure compared to the spherical shape of the Keggin ion. These data appear quite surprising because such large enthalpy gains observed for both 1:1 and 1:2 successive processes do not reflect anymore the weakness of

Table 1: Binding constants $K$ involving Dawson anion and tantalum octahedral cluster cation with $\gamma$-CD and associated thermodynamic parameters (in kcal.mol ${ }^{-1}$ ) at $T=298 \mathrm{~K}$.

\begin{tabular}{lllrrr}
\hline Guest & Step & $K\left(M^{-1}\right)$ & $\Delta_{\mathrm{r}} \mathrm{H}^{*}$ & $\mathrm{~T} \Delta_{\mathrm{r}} \mathrm{S}^{*}$ & $\Delta_{\mathrm{r}} \mathrm{G}^{*}$ \\
\hline$\left[\mathrm{P}_{2} \mathrm{~W}_{18} \mathrm{O}_{62}\right]^{6-}$ & $1: 1$ & $3.210^{3}$ & -12.6 & -7.8 & -4.8 \\
& $1: 2$ & $3.710^{2}$ & -11.9 & -8.4 & -3.5 \\
{$\left[\mathrm{Ta}_{6} \mathrm{Br}_{12}\left(\mathrm{OH}_{2}\right)_{6}\right]^{2+}$} & $1: 1$ & $1.510^{5}$ & -8.2 & -1.2 & -7.0 \\
& $1: 2$ & $1.310^{5}$ & -5.2 & +1.9 & -7.0 \\
\hline
\end{tabular}

the intermolecular interactions of the Dawson ion with the $\gamma$-CD. Actually, a partial inclusion could be expected involving the two polar sites of the Dawson ion, structurally similar to that found by Stoddart et al. with the Keggin ion derivative. ${ }^{11}$ Nevertheless, as evidenced by our ${ }^{1} \mathrm{H}$ NMR studies in solution and supported by $\mathrm{X}$-ray diffraction analysis, aggregates formation results mainly from close contacts between the largest lateral sides of the POM and the hydrophilic primary face of the $\gamma$-CD species. Furthermore, overall results are rather consistent with weak interactions as shown by ${ }^{1} \mathrm{H}$ NMR in solution and solid state structural analysis even though the resulting aggregates exhibit fair stability as exemplified by large variations of self-diffusion coefficient of both species (see DOSY NMR in Figure 4) and by large binding constants $K_{11}$ and $K_{12}$. These apparent inconsistencies fade away whilst the prime role of the solvent is considered. Since a pure hydrophobic effect cannot account within the interacting process, water structure recovery resulting of solvent depletion from binding interfaces should contribute in a significant extent. Thermodynamic fingerprints (see Table 1) could be consistent with a "chaotropic" recognition process involving "water structure breakers" species. This idea that POM anions can range in the chaotropic category is supported by the low charge density distributed at the POM surface and by the intrinsic weak ability of the POM anion to be strongly solvated. Furthermore, evidences of interaction between Keggin-type POMs and organic materials such as lipids or biomolecules are also consistent with the chaotropic nature of POMs. ${ }^{31}$

Guest affinity of $\left[\mathrm{Ta}_{6} \mathrm{Br}_{12}\left(\mathrm{H}_{2} \mathrm{O}\right)_{6}\right]^{2+}$ octahedral cluster has been determined by ITC titration experiments which have been analyzed using a two-step sequential binding model (see Figure 7). The thermodynamic parameters and binding constants included in 
Table 1 and Figure 7 reveal that both 1:1 and 1:2 processes are enthalpy driven and associated to opposite entropy changes which is slightly unfavorable for the first 1:1 step and then switches to positive for the following 1:2 step. Binding constants related to the sequential host-guest recognition exhibit very high values such as $K_{11}=1.510^{5} \mathrm{M}^{-1}$ and $K_{12}=1.310^{5} \mathrm{M}^{-1}$, which are comparable to that reported by Nau et al. on the 1:1 binding process between $\gamma-\mathrm{CD}$ and the perhalogenated dodecaborate ion $\left[\mathrm{B}_{12} \mathrm{X}_{12}\right]^{2-}$ $(\mathrm{X}=\mathrm{F}, \mathrm{Cl}, \mathrm{Br}$ and $\mathrm{I})$. Among the series, the highest binding constant was obtained with the bromo-derivative $\left[\mathrm{B}_{12} \mathrm{Br}_{12}\right]^{2-}$ with $K_{11}$ $=9.610^{5} \mathrm{M}^{-1}$ that led the authors to conclude that size-matching effect and polarizability of the $\mathrm{X}$ groups should contribute to the host-guest recognition process. In our case, the $\left\{\mathrm{Ta}_{6} \mathrm{Br}_{12}\left(\mathrm{H}_{2} \mathrm{O}\right)_{6}\right]^{2+}$ cationic guest exhibits similar globular shape and size to those of the $\left[\mathrm{B}_{12} \mathrm{Br}_{12}\right]^{2-}$ anion. ${ }^{27}$ Furthermore, the positive charge of the cluster does not affect anymore the host-guest affinity which rivals and even exceeds usual values found for $\gamma-\mathrm{CD}$ with anionic substrates. $^{32,26 a}$ Such a large affinity corroborates nicely the $\mathrm{X}$ Ray diffraction analysis and solution ${ }^{1} \mathrm{H}$ NMR. In the solid state, the identified network of convergent weak hydrogen bonding interactions should obviously contribute in part as pulling factor to the supramolecular assembly stability. Actually, formation of this host-guest arrangement in aqueous medium remains very intriguing because both components are considered as hydrophilic units, mainly due to the six aqua ligands located at the corner of the dicationic octahedral cluster or due to the 24 hydroxyl groups that line the primary and the secondary face of the $\gamma$-CD. Hence, the role of the solvent should be pointed out, acting as a pushing factor which consists of self-reorganization of water molecules relocated from the solvation shell to the bulk. Such a contribution has been considered by Nau et al. as the main factor governing the inclusion process, due to the chaotropic or super chaotropic nature of the dodecaborate series. ${ }^{27,33}$ This example gives first indications about the solvated character of the hexatantalum cluster and should be the starting point for further development using various octahedral type clusters that differ in their metallic centers, inner or outer ligands or ionic charge. ${ }^{34,14 b}$

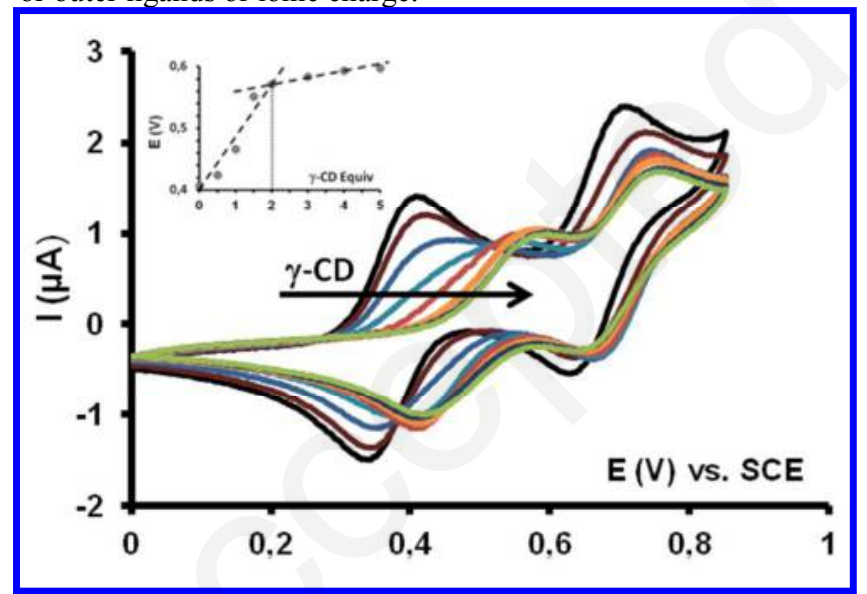

Figure 8. Cyclovoltammograms of $\left[\mathrm{Ta}_{6} \mathrm{Br}_{12}\left(\mathrm{H}_{2} \mathrm{O}\right)_{9}\right]^{2+}(0.5 \mathrm{mM}, 298 \mathrm{~K}$, scan rate $10 \mathrm{mV} . \mathrm{s}^{-1} ; 2.510^{-2}$ mol. $\mathrm{L}^{-1} \mathrm{HClO}_{4}$ aqueous solution) in the presence of increasing amounts of $\gamma$-CD (from 0 to 5 equivalents). Insert : plot of the first anodic peak potential versus equivalent number of $\gamma$-CD showing a break point for the stoichiometric conditions.

Electrochemistry. As both inorganic moieties are redox active and display complementary electrochemical properties, influence of $\gamma$-CD upon the electrochemical properties have been examined. Dawson anion $\left[\mathrm{P}_{2} \mathrm{~W}_{18} \mathrm{O}_{62}\right]^{6-}$ exhibits the general electrochemical behavior of POM compounds that corresponds to ability to under- go quasi-reversible multi-electron reductions, ${ }^{35}$ thus confering electrons reservoir properties interesting for many applications with regard to energy conversion or storage. ${ }^{36}$ Whatever the equivalent number of $\gamma-\mathrm{CD}$, cyclovoltammograms (CVs) of the Dawson remain almost unchanged with respect to that previously reported for the CD-free Dawson anion (not shown). ${ }^{35}$ Such results are probably the fingerprint of labile and weakly bound adducts POM@nCD, previously identified by ${ }^{1} \mathrm{H}$ NMR and by structural analysis. Conversely, the electron-rich $\left[\mathrm{Ta}_{6} \mathrm{Br}_{12}\left(\mathrm{H}_{2} \mathrm{O}\right)_{6}\right]^{2+}$ cluster gives two successive monoelectronic waves observed at $\mathrm{E}_{1}{ }^{\circ}=+0.37 \mathrm{~V}$ and $\mathrm{E}_{2}{ }^{\circ}=+0.67 \mathrm{~V} v s$. SCE in 0.025 mol.L $\mathrm{L}^{-1} \mathrm{HClO}_{4}$ aqueous solution (see Figure 8). ${ }^{37}$ These monoelectronic transfers are reversible $\left(\Delta \mathrm{E}_{\mathrm{p}} \sim 60 \mathrm{mV}\right)$ and correspond to the redox couples $\left\{\mathrm{Ta}_{6}\right\}^{2+} /\left\{\mathrm{Ta}_{6}\right\}^{3+}$ and $\left\{\mathrm{Ta}_{6}\right\}^{3+} /\left\{\mathrm{Ta}_{6}\right\}^{4+}$, respectively. Upon addition of $\gamma-\mathrm{CD}$, these two redox peaks shift gradually toward higher potential with a large change for the first exchange $\left(\Delta \mathrm{E}_{1}{ }^{\circ}=+130 \mathrm{mV}\right)$ and a smaller one for the second $\left(\Delta \mathrm{E}_{2}{ }^{\circ}=+30 \mathrm{mV}\right)$. These observations evidences clearly that binding situation occurs altering significantly the electrochemical properties of the guest. In addition, loss of electrochemical reversibility is observed and characterized by an increase of potential difference between the cathodic and anodic peaks $\Delta \mathrm{E}_{\mathrm{p}}$ of $140 \mathrm{mV}$ and $100 \mathrm{mV}$ for the first and the second exchange, respectively. Then, changing the charge state of the guest from $2+$ to $4+$ in the non-polar environment of the $\gamma$-CD pocket might be difficult and should affect the thermodynamic stability of the host-guest assembly giving rise to the observed redox shifts and change of the kinetic barrier. In accordance with this reasonable and welldocumented assumption, ${ }^{38}$ the UV-vis spectrum of the cluster undergoes only very small variations, indicating that electronic structure of the reduced state of the cluster is almost unaffected by $\gamma$-CD complexation (see SI §7). These preliminary results tend to demonstrate that electrochemical changes should involve mainly the oxidized forms, namely $\left\{\mathrm{Ta}_{6}\right\}^{3+}$ and $\left\{\mathrm{Ta}_{6}\right\}^{4+}$. Nevertheless, ongoing works are in progress including spectro-electrochemistry and characterization of the specific interactions of the $\gamma-C D$ with the oxidized states $\{\mathrm{Ta}\}^{3+}$ and $\{\mathrm{Ta}\}^{4+}$.

\subsection{Three-component supramolecular system.}

The overall presented results offer fundamental bases to build hybrid materials based on combination of three components such as $\gamma-\mathrm{CD}$, the cationic octahedral cluster $\left[\mathrm{Ta}_{6} \mathrm{Br}_{12}\left(\mathrm{H}_{2} \mathrm{O}\right)_{6}\right]^{2+}$ and the Dawson-type POM. The $\gamma$-CD component exhibits a remarkable high affinity with the cationic cluster to consider the 1:2 resulting host-guest complex as a highly stable cationic hybrid building block. Besides, the Dawson $\left[\mathrm{P}_{2} \mathrm{~W}_{18} \mathrm{O}_{62}\right]^{6-}$ anion and the $\gamma-\mathrm{CD}$ constitutes a versatile chemical system able to form supramolecular adducts which differ from their stoichiometry but are invariably built on a selective interplay mode involving the primary face of the $\gamma-\mathrm{CD}$ and the largest side of the POM (see Figure 2a-c). Then, high affinities, selective interactions and dynamic flexibility are harnessed to associate the ditopic hybrid cation and the polyoxometalate unit together. This approach will offer undoubtedly new perspectives in the design of unprecedented functional materials that combine the key properties of the electron-rich (cluster donor) and the electron-poor (POM acceptor) moieties, both specifically and spontaneously associated by $\gamma$ $\mathrm{CD}$ as ditopic linker. Besides, it should be mentioned that mixing the POM and cluster components in similar conditions but in absence of the $\gamma-\mathrm{CD}$, amorphous and poorly defined materials were systematically obtained. Furthermore, ITC measurements on the POM-cluster binary system does not allow detecting any significant heat exchange, consistent with no direct POM•••cluster interaction in such conditions. 
From hydrogel to single crystals. First attempts have been carried out by mixing directly $2.10^{-2}$ mol. $\mathrm{L}^{-1}$ aqueous solutions containing the ditopic hybrid cation $\left\{\mathrm{Ta}_{6} \mathrm{Br}_{12}\left(\mathrm{H}_{2} \mathrm{O}\right)_{6} @ 2 \mathrm{CD}\right\} \mathrm{Br}_{2} \cdot 14 \mathrm{H}_{2} \mathrm{O}$ and the POM $\mathrm{K}_{6} \mathrm{P}_{2} \mathrm{~W}_{18} \mathrm{O}_{62} \cdot 19 \mathrm{H}_{2} \mathrm{O}$. In such conditions, the resulting greenish solution becomes viscous until complete gelification in few minutes. Formation of hydrogel-type material indicates that metathesis reaction takes place and results in polymerization process involving the ditopic cation and the POM. The hydrogel has been characterized through a set of analytical methods revealing composition consistent with the formula $\mathrm{K}_{4}\left[\mathrm{Ta}_{6} \mathrm{Br}_{12}\left(\mathrm{H}_{2} \mathrm{O}\right)_{6}\right][\gamma$ $\mathrm{CD}]_{2}\left[\mathrm{P}_{2} \mathrm{~W}_{18} \mathrm{O}_{62}\right] \cdot \mathrm{nH}_{2} \mathrm{O}$. Infrared spectra confirm the incorporation of the three components assembled within the hydrogel network (see Figure S2, SI §3). Besides, the hydrogel assembly reveals birefringence properties below polarized optical micrograph but the most surprising outcome is probably the presence of diffraction peaks in the powder X-Ray diffraction diagram that suggests long-range order exists to a certain extent (see Figure 9). Such a result prompts us to get single-crystals from slow-diffusion techniaues using conventional H-tube method. From similar $2.10^{-2}$

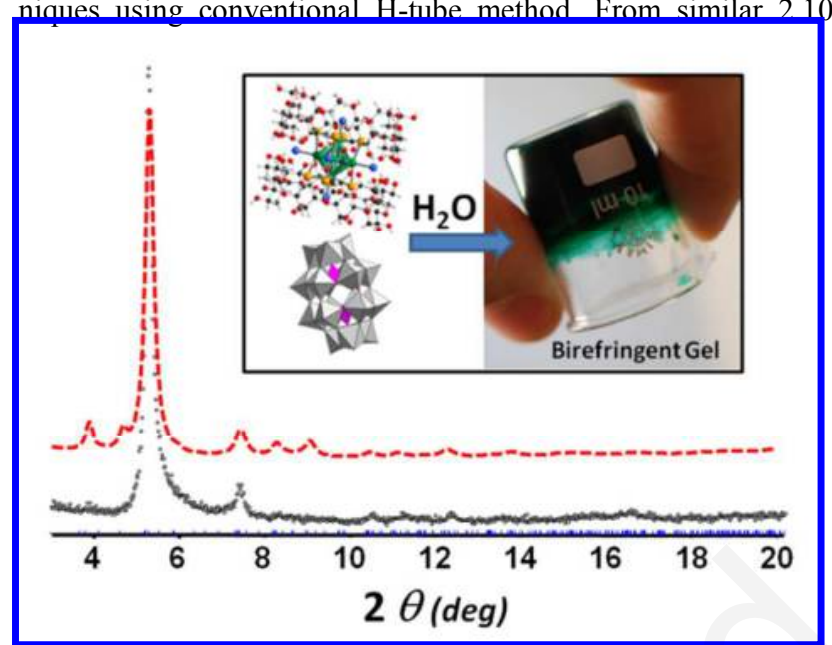

Figure 9. Powder-X-Ray diffraction diagram of the three-component hydrogel assembly built from hierarchical organization of $\gamma$ cyclodextrin, polyoxometalate $\left[\mathrm{P}_{2} \mathrm{~W}_{18} \mathrm{O}_{62}\right]^{6-}$ and octahedral cluster $\left\{\mathrm{Ta}_{6}\right\}^{2+}$ (see insert); experimental (black) and calculated from singlecrystal X-Ray diffraction data (red).

mol. $L^{-1}$ aqueous solutions used for the hydrogel preparation, small but well-shaped greenish single-crystals suitable for X-ray diffraction analysis were formed in the interfacial region of both solutions for about one week. Elemental analysis of crystals, supported by usual set of analytical methods leads to the similar composition found for the hydrogel-based material with the formula $\mathrm{K}_{2} \mathrm{H}_{2}\left\{\left[\mathrm{Ta}_{6} \mathrm{Br}_{12}\left(\mathrm{H}_{2} \mathrm{O}\right)_{6}\right] @\left(\mathrm{C}_{48} \mathrm{H}_{80} \mathrm{O}_{40}\right)_{2}\right\}\left[\mathrm{P}_{2} \mathrm{~W}_{18} \mathrm{O}_{62}\right] \cdot 32.5 \quad \mathrm{H}_{2} \mathrm{O}$ (abbreviated $\left\{\mathrm{Ta}_{6} @ 2 \mathrm{CD} \cdot \mathrm{POM}\right\}$ ). In this regard, POM, $\gamma-\mathrm{CD}$ and $\left\{\mathrm{Ta}_{6}\right\}$ octahedral cluster behave as a versatile system, allowing a structuring control from hydrogel to single-crystals using supramolecular bottom-up approach.

Single-crystal X-ray diffraction analysis of the threecomponent system. Single-crystal X-ray diffraction study of $\left\{\mathrm{Ta}_{6} @ 2 \mathrm{CD} \cdot \mathrm{POM}\right\}$ reveals a 1D infinite sandwich-type structure wherein the Dawson POM anions alternate with the ditopic supramolecular cation $\left\{\mathrm{Ta}_{6} @ 2 \mathrm{CD}\right\}^{2+}$ (see Figure 10). The linear infinite ionic polymers run along the $c$ axis and stack together symmetrically as parallel pillars to give tetragonal packing (see Figure 10b). Besides, the ditopic hybrid cation incorporated within the three-component system exhibits very close geometrical features that those observed previously in the crystallographic structure of $\left[\mathrm{Ta}_{6} \mathrm{Br}_{12}\left(\mathrm{H}_{2} \mathrm{O}\right)_{6}\right] \cdot[\gamma-\mathrm{CD}]_{2} \mathrm{Br}_{2} \bullet 14 \mathrm{H}_{2} \mathrm{O}$ (see Figure 3), especially with regard to the host-guest interactions, mainly expressed through hydrogen bonds distribution. In a same way, arrangement between the $\gamma-\mathrm{CD}$ and the POM remains quite unchanged and involves primary faces of the $\gamma-\mathrm{CD}$, similar to the structural models of POM@nCD, depicted in Figure 2. Interesting observations can be noticed with regard to the expression of the chirality within the solid state arrangement. As usually observed with solid-state structures of cyclodextrins, the $\left\{\mathrm{Ta}_{6} @ 2 \mathrm{CD} \cdot \mathrm{POM}\right\}$ crystallographic structure is consistent with the $P 4_{1} 2_{1} 2$ chiral space group which imposes $4_{1}$ helicoidal axis along centers of the tubular chains. Then, related $4_{1}$ operations generate four different positions for the POM units that wheel helicoidally around the tube axis while orientation of the $\left\{\mathrm{Ta}_{6} @ 2 \mathrm{CD}\right\}^{2+}$ units remain unchanged (see Figures 10a and 10c).
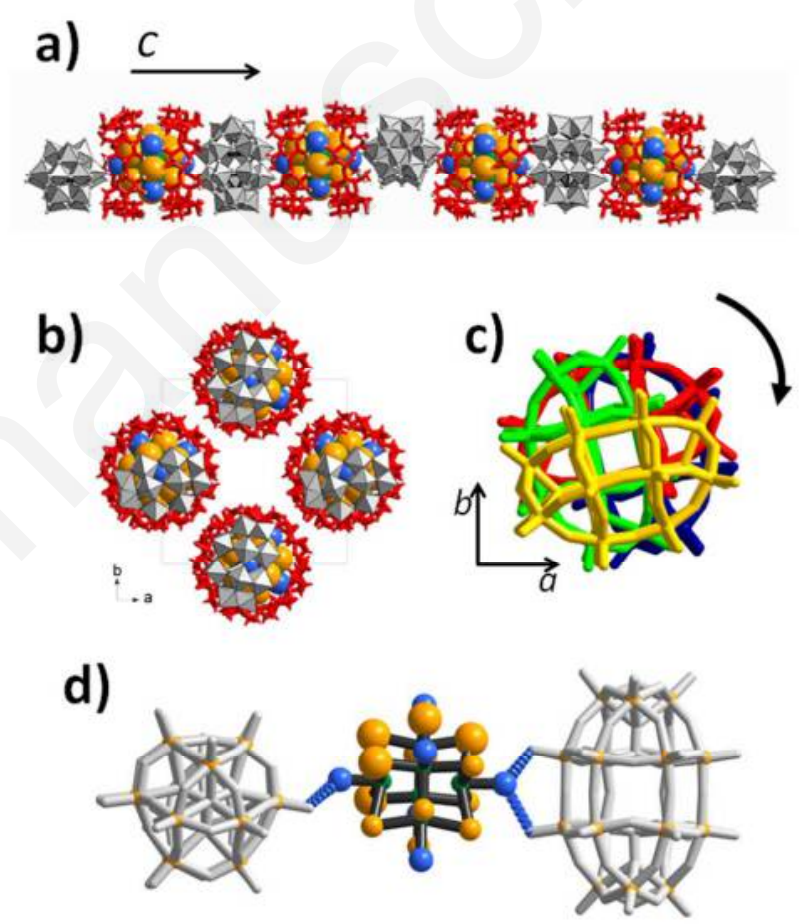

Figure 10. Structural representations resulting from the single-crystal $\mathrm{X}$-ray diffraction analysis of the three-component system $\left\{\mathrm{Ta}_{6} @ 2 \mathrm{CD} \cdot \mathrm{POM}\right\}$ : a) tubular chain showing periodic alternation of the ditopic cation $\left\{\mathrm{Ta}_{6} @ 2 \mathrm{CD}\right\}^{2+}$ and the $\left[\mathrm{P}_{2} \mathrm{~W}_{18} \mathrm{O}_{62}\right]^{6-} \mathrm{POM}$ running along $c$ axis with $c=89.17 \AA$; b) highlight of the tubular chain packing in the $a b$ plane; c) POM moieties within the tubular chain are symmetrically related through $4_{1}$ helicoidal axis generating successively four equivalent POM units colored in yellow, green, red and blue, respectively; d) highlight of two POM units sandwiching the $\left\{\mathrm{Ta}_{6}\right\}^{2+}$ cluster through short hydrogen bonds such as $\mathrm{O}-\mathrm{O}=2.64 \AA$ (the two $\gamma$-CD have been omitted for clarity).

Finally, additional hydrogen bonds are found, which involve the axial aqua ligand of the $\left\{\mathrm{Ta}_{6} \mathrm{Br}_{12}\left(\mathrm{H}_{2} \mathrm{O}\right)_{6}\right\}^{2+}$ and terminal oxygen atoms of the POM. The shortest distances $\mathrm{O} \cdots \mathrm{O}$ that are in the 2.64-2.83 $\AA$ range suggest that electrostatic interactions may reinforce hydrogen bonding. Besides, the long-range ordering within the hydrogel can be understood partly from the structural 
analysis of the single-crystals, by considering that stacked tubular chains, shown in Figure 10 are flexible enough to selfinterpenetrate in the supramolecular 3D network. Nevertheless, further investigations are still progressing for the full understanding of the long-range ordering of our hybrid hydrogel.

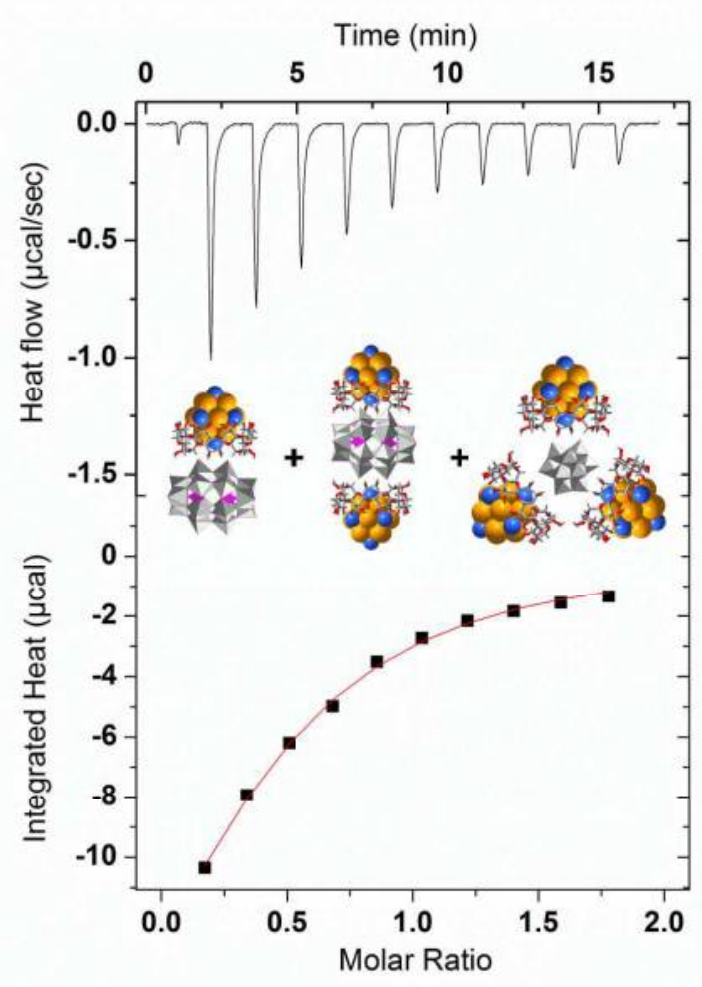

Figure 11. ITC thermograms (upper part) and isotherms (lower part) for the titration of a mixture of $\gamma-\mathrm{CD}(22.5 \mu \mathrm{M})$ and $\left[\mathrm{Ta}_{6} \mathrm{Br}_{12}\left(\mathrm{H}_{2} \mathrm{O}\right)_{6}\right]^{2+}$ $(90 \mu \mathrm{M})$, by a $200 \mu \mathrm{M}$ POM solution. Dots correspond to the experimental heats. Red line corresponds to the theoretical heats when considering the presence of $\left\{\mathrm{Ta}_{6}\right\} @ \mathrm{CD}, \quad\left\{\mathrm{Ta}_{6}\right\} @ 2 \mathrm{CD}$, $\operatorname{POM}\left[\left\{\mathrm{Ta}_{6}\right\} @ \mathrm{CD}\right], \operatorname{POM}\left[\left\{\mathrm{Ta}_{6}\right\} @ \mathrm{CD}\right]_{2}$ and $\operatorname{POM}\left[\left\{\mathrm{Ta}_{6}\right\} @ \mathrm{CD}\right]_{3}$

ITC measurements. As $\left[\mathrm{P}_{2} \mathrm{~W}_{18} \mathrm{O}_{62}\right]^{6-}$ and $\left[\mathrm{Ta}_{6} \mathrm{Br}_{12}\left(\mathrm{H}_{2} \mathrm{O}\right)_{6}\right]^{2+}$ proved their ability to form various supramolecular complexes with $\gamma-\mathrm{CD}$, the possibility of forming materials involving the three partners was then explored by ITC. Interestingly, when POM was injected on a mixture of $\left\{\mathrm{Ta}_{6}\right\}$ and $\gamma-\mathrm{CD}$, significant heats were systematically recorded, whereas negligible signals should be expected in the hypothesis of a simple competition between the two distinct $1: 1$ and 1:2 $\gamma$-CD complexes of POM and $\left\{\mathrm{Ta}_{6}\right\}$, as the $\left\{\mathrm{Ta}_{6}\right\}$ complexes are significantly stronger than those involving POM (See SI $\S 6$ for simulation details). These heats demonstrated the existence of hetero-ternary complexes.

On one hand, when the initial concentrations of $\left\{\mathrm{Ta}_{6}\right\}$ and $\gamma-\mathrm{CD}$ lead essentially to $1: 1$ complexes, a clean thermogram was obtained (see Figure 11). Strikingly, the corresponding binding isotherm has been calculated with a satisfactory agreement with the experimental data by considering the possibility to associate up to three $\left\{\mathrm{Ta}_{6} @ \mathrm{CD}\right\}^{2+}$ complexes with one POM molecule, as illustrated in Figure 11. The estimated binding constant for the interaction between one $\left\{\mathrm{Ta}_{6}\right\} @ \mathrm{CD}$ complex with one POM molecule was close to $410^{4} \mathrm{M}^{-1}$, which is one order of magnitude higher than that for fixing one $\gamma$-CD on one POM molecule in the absence of $\left\{\mathrm{Ta}_{6}\right\}$. Actually, it has to be stressed that the quantitative analysis of this single isotherm by our theoretical model is probably over-parametrized, with respect to the presence of a large distribution of aggregates arising from available combinations of the three building blocks. Nevertheless, the rapid decrease of the ITC isotherm is clearly in favor of strong and multiple bindings between POM and $\left\{\mathrm{Ta}_{6}\right\} @$ CD entities.

On the other hand, when $\left\{\mathrm{Ta}_{6}\right\} @ 2 \mathrm{CD}$ complexes were initially favored in the cell by increasing the initial $\gamma-\mathrm{CD}$ concentration, important deformations were observed on the ITC thermograms (see Figure S18, SI §7). Concomitantly, turbid solutions were extracted from the cell at the end of the titrations. Such observations indicate that interactions between the ditopic $\left\{\mathrm{Ta}_{6} @ 2 \mathrm{CD}\right\}$ cationic complexes and the POM favor polymerization process. Both observations of deformed thermograms and turbid solutions during the ITC experiment corroborate our previous observations that such ternary system leads to supramolecular polymer. Unfortunately, the consecutive variation of viscosity and the heterogeneous character of the solutions hindered any quantitative interpretation of the ITC thermograms for further characterizations about interactions between POM and $\left\{\mathrm{Ta}_{6}\right\} @ 2 \mathrm{CD}$ complexes.

\section{CONCLUSIONS}

We have shown that recognition process of $\gamma$-cyclodextrin in hostguest binding can be used for the building of hierarchical noncovalent materials using POMs and octahedral clusters. We report discovery of a remarkable versatility featuring interactions between the Dawson anion $\left[\mathrm{P}_{2} \mathrm{~W}_{18} \mathrm{O}_{62}\right]^{6-}$ and the primary portal of $\gamma$ $\mathrm{CD}$ allowing the selective isolation of the $1: 1,1: 2$ or $1: 3$ adducts in the solid state. We report also on the first inclusion complex built from a cationic octahedral cluster $\left[\mathrm{Ta}_{6} \mathrm{Br}_{12}\left(\mathrm{H}_{2} \mathrm{O}\right)_{6}\right]^{2+}$ and $\gamma$ $\mathrm{CD}$ wherein the structural model displays the conventional hostguest 1:2 assembly involving close intermolecular contacts. Solution studies, including NMR methods, ITC and electrochemistry reveal that organic and inorganic moieties are pre-assembled together in solution for giving stable aggregates while all these species are considered as hydrophilic. Such a behavior gives insights about the true nature of these solvated ions which seem to range within the category of chaotropic species. Nevertheless, given the large structural diversity of both classes of compounds, offering species that differ in their composition, shape, size, symmetry and ionic charge, there should be extensive solution chemistry to determine the factor dictating their supramolecular interplay with substrates of interest.

Besides, the $\{\mathrm{POM} @ \mathrm{nCD}\}^{6-}$ aggregates and the ditopic $\left\{\mathrm{Ta}_{6} @ 2 \mathrm{CD}\right\}^{2+}$ arrangement reveal striking complementary structural and chemical properties, which have been exploited successfully to design novel three-component phases derived as supramolecular hydrogel or single-crystals with similar composition. XRay diffraction study shows that in the supramolecular assembly, $\left\{\mathrm{Ta}_{6} @ 2 \mathrm{CD}\right\}^{2+}$ acts as a ditopic ionic linker able to produce 1D tubular chain resulting from periodic alternation of POMs and clusters. This first example highlights promising route to design a new class of responsive and adaptable multifunctional materials built from deliberate associations of functionalities by the three well-ordered components. As instance, combination of luminescent clusters ${ }^{16}$ as solar light sensitizer with POMs as electron acceptor could be useful to design light-driven devices relevant in photocatalysis or chemical detection. Given the scope of these domains, including POM and cluster chemistries, there is great interest to develop relevant hybrid multifunctional materials using the straightforward supramolecular approach. This strategy will pave the way toward exciting, extensive and challenging physicalchemistry or physics in this new area. 


\section{ASSOCIATED CONTENT}

\section{Supporting Information}

General methods ( 1 ); syntheses ( $(2)$; FT-IR spectra ( 3$)$; single crystal X-Ray diffraction (\$4) including crystallographic parameters and additional figures; NMR data (§5), ITC measurements (§6) and UV-Visible spectra (§8). "This material is available free of charge via the Internet at http://pubs.acs.org."

\section{AUTHOR INFORMATION}

\section{Corresponding Author}

*emmanuel.cadot@uvsq.fr

*mohamed.haouas@uvsq.fr

\section{Notes}

The authors declare no competing financial interests.

\section{ACKNOWLEDGMENT}

The Authors gratefully acknowledge financial support from LIACNRS CLUSPOM and LABEX CHARMMMAT. We are grateful to Dr. William Sheppard for allowing access to X-Ray synchrotron facilities at PROXIMA2 source, SOLEIL laboratory, to Dr Nathalie Guillou for powder XRDP, Mrs My-An Tran for electrochemical experiments, Mrs Noée Dumait and Mr Serge Paofai for cluster synthesis. We would like to express our gratitude to Dr. Jöelle Thuriot from University of Lille 1 conducting the ICP analyses (REALCAT Plateform, École Centrale Lille)

This work was also supported by University of Versailles Saint Quentin, CNRS and région Ile de France through DIM Nano K.

\section{REFERENCE}

(1) (a) Lehn J.-M. Angew. Chem. Int. Ed. 1988, 27, 89-112. (b) Hao, C.; Liu, Y.; Chen, X.; Li, J.: Zhang, M.; Zhao Y.; Wang, Z. Small, 2016, 12, 1825-1839. (c) Ding, Y.; Yu, G. Angew. Chem. Int. Ed. 2016, 55, 47724776. (d) Click, K.-A.; Beauchamp, D. R.; Huang, Z.; Chen, W. ; Wu, Y. J. Am. Chem. Soc., 2016, 138,1174-1179. (e) Webber, M. J.; Appel, E. A. ; Meijer, E. W. ; Langer, R. Nature Mat. 2016, 15, 13-26. (f) Langer, R.; Tirrell, D. A. Nature, 2004, 428, 487-492.

(2) Whitesides, G. M.; Kriebel, J. K.; Mayers, B. T. Self-Assembly and Nanostructured Materials: Springer: Berlin, 2005.

(3) (a) Suh, J. Adv. Supramol. Chem. 2000, 6, 245-286.; (b) Fersht, A. R. Structure and Mechanism in Protein Science, W. H. Freeman, new York, 2000.

(4) (a) Kennan, A. J.; Whitlock, H. W. J. Am. Chem. Soc. 1996, 118, 3027-3028. (b) Kim, J.-H.; Nam, D.-H.; Park, C.- B. Curr. Opin. Biotechnol. 2014, 28, 1-9. (c) J. A. Maciá.-Agullò, A. Corma, H. Garcia, Chem. Eur.J. 2015, 21, 10940-10959.

(5) (a) Raymo, F. M.; Stoddart, J. F. Current Opinion in Colloid \& Interface Science, 1996, 1, 116-126. (b) Tiekink, E. R. T. Coord. Chem. Rev. 2017, 345, 209-228. (c) Amabilino, D. B.; Smith, D. K.;Steed J. W. Chem. Soc. Rev. 2017, 46, 2404-2420.

(6) (a) Eisenberg, D.; McLachlan, A. D. Nature, 1986, 319, 199-203.(b) Tanford, C. The hydrophobic Effect : Formation of Micelles and biological Membranes, Wiley, New York, 1980. (c) Lazaridis, T. Acc. Chem. Res. 2001, 34, 931-937.

(7) (a) Diederich, F. Angew. Chem. Int. Ed. 1988, 27, 362-386.(b) Blokzijl, W.; Engberts, J. B. F. N. Angew. Chem. Int. Ed. 1993, 32, 15451579.

(8) (a) Special issue on polyoxometalates: Cronin L. and Müller A. Chem. Soc. Rev., 2012, 41, 7333-7334; (b) Dolbecq, A.; Dumas, E.; Mayer, C.
R.; Mialane, P. Chem. Rev. 2010, 110, 6009-6048; (c) Hill, C. L. Chem. Rev. 1998, 98, 1; (d) Pope, M. T. Heteropoly and IsopolyOxometalates; Springer-Verlag: New York, 1983.

(9) (a) Fraqueza, G.; Ohlin, C. A.; Casey, W. H.; Aureliano, M. J. Bio Chem. 2012, 107, 82-89. (b) Clemente-Juan, J. M.; Coronado, E.; GaitaArino, A. Chem. Soc. Rev. 2012, 41, 7464-7478; (c) Vilà-Nadal, L.; Mitchell, S. G.; Markov, S.; Busche, C.; Georgiev, V.; Asenov, A.; Cronin L. Chem. Eur. J. 2013, 19, 16502 - 16511. (d) Baldoví, J. J.; ClementeJuan, J. M.; Coronado, E.; Duan, Y.; Gaita-A riño, A.; Giménez-Saiz, C. Inorg. Chem. 2014, 53, 9976-9980. (e) Katryniok, B.; Paul, S.; Capron, M.; Lancelot, C.; Bellière-Baca, V.; Rey, P. ; Dumeignil, F. Green Chem., 2010, 12, 1922-1925; (f) Katryniok, B.; Paul, S.; Dumeignil, F. ACS Catal. 2013, 3, $1819-1834$.

(10) Yue, L.; Wang, S.; Zhou, D.; Zhang, H.; Li, B.; Wu, L. Nature Comm. 2016, 7, 10742.

(11) Wu, Y.; Shi, R.; Wu, Y.-L; Holcroft, J. M.; Liu, Z.; Frasconi, M.; Wasielewski, M. R.; Li, H.; Stoddart, J. F. J. Am. Chem. Soc. 2015, 137, 4111-4118.

(12) a) Naumov, N. G.; Brylev, K. A.; Mironov, Y. V.; Cordier, S.; Fedorov, V. E. J. of Struct. Chem. 2014, 55, 1371-1389. b) Fedorov, V. J. Clust. Sci. 2015, 26, 3-15. c) Cordier, S. ; Grasset, F. ; Molard, Y.; Amela-Cortes, M. ; Boukkherroub, R. Ravaine, S. ; Mortier, M. ; Ohashi, N. ; Saito, N. ; Haneda, H. J. Inorg. Organomet. Polym. 2015, 25, 189-204.

(13) Sergent, M. ; Perrin, C. ; Ihmaine, S. ; Perrin, A. ; Ben Yaich, H. ; Pena, O.; Chevrel, R. ; Gougeon, P. ; Potel, M. J. Chim. Phvs. 1991, 88, 2123-2142.

(14) (a) Long, J. R.; McCarty, L. S.; Holm, R. H. J. Am. Chem. Soc. 1996, 118, 4603-4616. (b) Gabriel, J.-C. P.; Boubekeur, K.; Uriel, S. ; Batail, P. Chem.Rev. 2001, 101, 2037-2066.

(15) (a) Garreau, A.; Massuyeau, F.; Cordier, S.; Molard, Y.; Gautron, E.; Bertoncini, P.; Faulques, E.; Wery, J.; Humbert, B.; Bulou, A.; Duvail. ACS Nano, 2013, 7, 2977-2987. (b) Cîrcu, V.; Molard, Y.; Amela-Cortes, M.; Bentaleb, A.; Barois, P.; Dorcet, V.; Cordier, S. Angew. Chem., Int. Ed. 2015, 54, 10921-10925.

(16) Feliz, M.; Puche, M.; Atienzar, P.; Concepcion, P.; Cordier, S.; Molard, Y. ChemSusChem. 2016, 9, 1963.

(17) Molard, Y. Acc. Chem. Res. 2016, 49, 1514-1523.

(18) Neaime, C. ; Amela-Cortes, M. ; Grasset, F. ; Molard, Y. ; Cordier, S. ; Dierre, B. ; Mortier, M. ; Takei, T.; Takahashi, K. ; Haneda, H. ; Verelst, M. ; Lechevallier, S. Phvs. Chem. Chem. Phvs. 2016, 18, 3016630173.

(19) Solovieva, A. O.; Vorotnikov, Y. A.; Trifonova, K. E.; Efremova, O. A.; Krasilnikova, A. A.; Brylev, K. A.; Vorontsova, E. V.; Avrorov, P. A.; Shestopalova, L. V.; Poveshchenko, A. F.; Mironov, Y. V.; Shestopalov, M. A. N. J. Mater. Chem. B, 2016, 4, 4839-4846.

(20) Chen Y.; Liu, Y. Chem. Soc. Rev., 2010, 39, 495-505.

(21) Davis, M. E.; Brewster, M. E. Nat. Rev. Drug. Disc. 2004, 3, 1023 1035.

(22) Arima, H. ; Motoyama, K. ; Higashi, T. Therapeutic Deliverv, 2017, $8,215-232$

(23) (a) Wenz, G. Angew. Chem., Int. Ed. Engl. 1994, 33, 803-822. (b) Wenz, G.; Han, B.-H.; Müller, A. Chem. Rev. 2006, 106, 782-817. (c) Hapiot, F.; Tilloy, S.; Monflier, E. Chem. Rev. 2006, 106, 767-781.

(24) Viswanathan, B.; Barden, C. J.; Ban, F.; Boyd, R. J. Mol. Phys. 2005, 103, 337-344.

(25) (a) Vojnović, M. ; Antolić, S. ; Kojić-Prodić, B.; Brničević, N. ; Miljak, M. ; Aviani, I. Z. anorg. allg. Chem. 1997, 623, 1997, 1247-1254. (b) Vojnović, M. ; Brničević N.; Bašica, I. ; Planinić, P. ; Giesterb, G. $\underline{Z}$. anorg. allg. Chem. 2002, 628, 4012408. (c) M. Vojnović, D. Jozić, G. Giester, B. Perić, P. Planinić and N. Brničević, Act. Crvst. C. 2002, 58, 219-220.

(26) (a) Rekharsky, M. V.; Inoue, Y. Chem. Rev. 1998, 98, 1875. (b) Kamitori, S.; Hirotsu, K.; Higuchi, T. J. Am. Chem. Soc. 1987, 109, 2409. (27) Assaf, K. I.; Ural, M. S.; Pan, F.; Georgiev, T.; Simova, S.; Rissanen, K.; Gabel, D.; Nau, W. M. Angew. Chem. Int. Ed. 2015, 54, 6852-6856. (28) Schneider, H.-J. ; Hacket, F.; Rüdiger, V. Chem. Rev. 1998, 98, $1755-1785$. 


\section{Page 11 of 11}

1

2

3

4

5

6

7

8

9

10

11

12

13

14

15

16

17

18

19

20

21

22

23

24

25

26

27

28

29

30

31

32

33

34

35

36

37

38

39

40

41

42

43

44

45

46

47

48

49

50

51

52

53

54

55

56

57

58

59

60

(29) Houk, K. N.; Leach, A. G.; Kim, S. P.; Zhang, X. Angew. Chem. Int. Ed. 2003, 42, 4872-4897.

(30) Menuel, S.; Azaroual, N.; Landy, D; Six, N.; Hapiot, F.; Monflier, E. Chem. Eur. J. 2011, 17, 3949 - 3955.

(31) Kobayashi, D.; Nakahara, H.; Shibata, O.; Unoura, K.; Nabika, H. J. Phys. Chem. C, 2017, 121, 12895.

(32) Cromwell, W. C.; Bystrom, K.; Eftink, M. R. J. Phvs. Chem. 1985, $89,326-332$

(33) (a) Harries, D. ; Rau, D. C.; Parsegian, V. A. J. Am. Chem. Soc. 2005, 127, 2184 - 2190. (b) Gibb, C. L. D. ; Gibb, B. C. J. Am. Chem. Soc. 2011, 133, 7344 - 7347; (c) Carnegie, R. S.; Gibb, C. L. D.; Gibb, B. C. Angew. Chem. Int. Ed. 2014, 53, $11498-11500$.

(34) (a) Perrin, A.; Perrin, C. C. R. Chim. 2012, 15, 815-836. (b) Dorman, W. C.; McCarley, R. E. Inorg. Chem. 1974, 13, 491-493.

(35) Sadakane, M. ; Steckhan, E. Chem. Rev., 1998, 98, 219-238.

(36) Wang, H.; Hamanaka, S.; Nishimoto, Y.; Irle, S.; Yokoyama, T.; Yoshikawa, H.; Awaga, K. J. Am. Chem. Soc. 2012, 134, 4918-4924.

(37) Cooke, N., E.; Kuwana, T.; Espenson, J. Inorg. Chem. 1971, 1081 1083.

(38) Kaifer, A.; Gómez-Kaifer, M. (2007). Supramolecular Electrochemistry. Wiley Blackwell. 